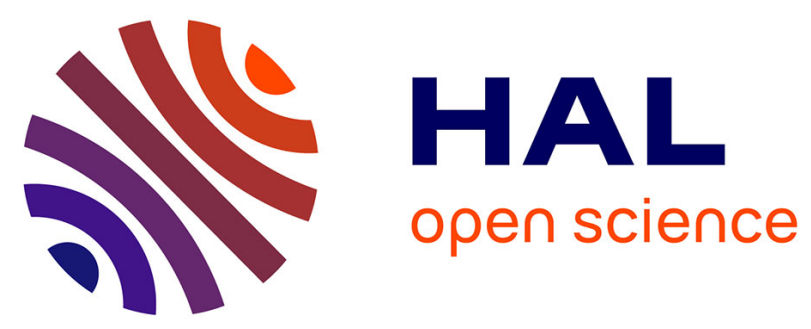

\title{
Near-surface mechanical heterogeneities in a dissimilar aluminum alloys friction stir welded joint
}

Damien Texier, Y. Zedan, T. Amoros, E. Feulvarch, J.C. Stinville, P. Bocher

\section{To cite this version:}

Damien Texier, Y. Zedan, T. Amoros, E. Feulvarch, J.C. Stinville, et al.. Near-surface mechanical heterogeneities in a dissimilar aluminum alloys friction stir welded joint. Materials \& Design, 2016, 108, pp.217-229. 10.1016/j.matdes.2016.06.091 . hal-01644878

\section{HAL Id: hal-01644878 \\ https://hal.science/hal-01644878}

Submitted on 13 Dec 2017

HAL is a multi-disciplinary open access archive for the deposit and dissemination of scientific research documents, whether they are published or not. The documents may come from teaching and research institutions in France or abroad, or from public or private research centers.
L'archive ouverte pluridisciplinaire HAL, est destinée au dépôt et à la diffusion de documents scientifiques de niveau recherche, publiés ou non, émanant des établissements d'enseignement et de recherche français ou étrangers, des laboratoires publics ou privés. 


\title{
Near-surface mechanical heterogeneities in a dissimilar aluminum alloys friction stir welded joint
}

\author{
D. Texier ${ }^{\text {a,* }}$, Y. Zedan ${ }^{\text {a }}$, T. Amoros ${ }^{\text {a,b }}$, E. Feulvarch ${ }^{\text {b }}$, J.C. Stinville ${ }^{\text {c }}$ P. Bocher ${ }^{\mathrm{a}}$ \\ ${ }^{a}$ Mechanical Engineering Department, École de Technologie Supérieure (ÉTS), 1100 Rue Notre-Dame Ouest, Montreal, H3C 1K3, Quebec, Canada \\ ${ }^{\mathrm{b}}$ Univ Lyon, ENISE, LTDS UMR 5513 CNRS, 58 rue Jean Parot, 42023 Saint-Etienne Cedex 02, France \\ c Materials Department, University of California Santa Barbara, 93106 Santa Barbara, CA, United States
}

\section{H I G H L I G H T S}

- Mechanical properties of a dissimilar aluminum alloys friction stir welded joint are investigated.

- Combination of OHR-DIC, EBSD and hardness measurements allows local characterization of the joint.

- Pronounced texture macroscopic bands are induced during welding process in the top region of the weld.

- The banded macrostructure, inducing strain localization under monotonic loading, is observed to be detrimental for the joint.

\section{A R T I C L E I N F O}

\section{Keywords:}

Friction stir welding (FSW)

Digital image correlation (DIC)

Electron backscattered diffraction (EBSD)

Texture

Aluminum alloys

Banded macrostructures

Microhardness

Dissimilar join
GRA P H ICA L A B S T R A C T

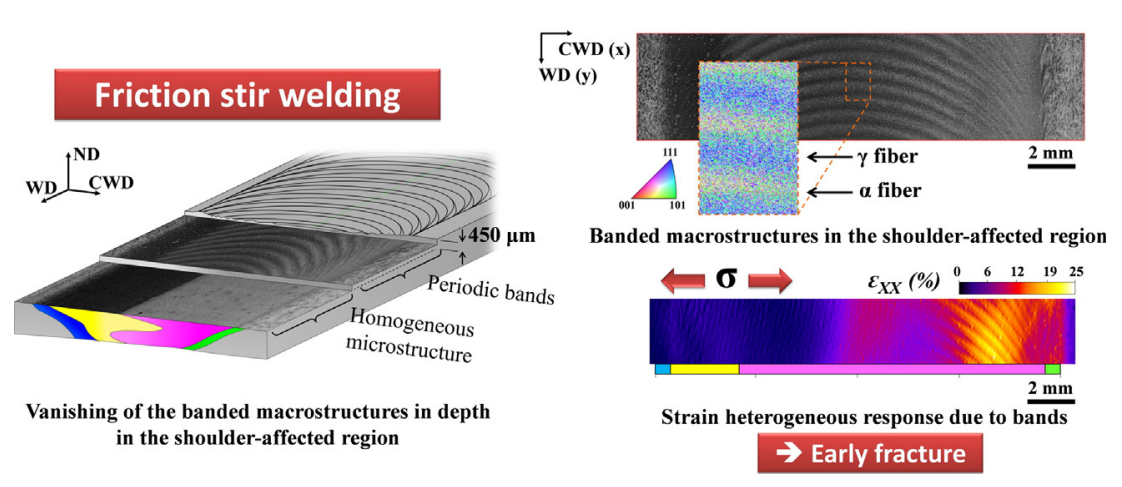

\section{A B S T R A C T}

The local mechanical properties of a dissimilar friction stir welded AA-2024-T3/AA-2198-T3 joint were documented during a uniaxial tensile test. High-resolution digital image correlation was performed during monotonic tensile tests to capture the local in-plane strain fields of the heterogeneous macrostructure of the weld. In the shoulder-affected region, banded macrostructures with heterogeneous mechanical properties were found. They were related to pronounced textures regions, which can be associated to strain-rate gradient during one rotation of the tool. The banded macrostructures in the nugget region were observed to be responsible for early plasticity in the joint and ultimately to be the fracture location of the weld. The heterogeneous mechanical response of the joint was also investigated by microhardness measurements. Differences were found between hardness and local tensile properties, demonstrating microhardness measurements can be misleading and only direct high-resolution digital image correlation techniques can document the mechanical behavior of materials having complex and heterogeneous micro-/macrostructures.
* Corresponding author.

E-mail addresses: damien.texier@etsmtl.ca (D. Texier), yasser.zedan@etsmtl.ca (Y.Zedan), thomas.amoros@enise.fr (T. Amoros), eric.feulvarch@enise.fr (E. Feulvarch), stinville@engineering.ucsb.edu (J.C. Stinville), philippe.bocher@etsmtl.ca (P. Bocher).

\section{Introduction}

Developing high-strength, fatigue, and fracture resistant welds for aluminum alloys is critical to design complex aerospace structural components [1]. Friction Stir Welding (FSW), a solid state welding technique 
which emerged as a solution to join high strength Al-alloys that are difficult to weld, is used to assemble AA-2XXX and AA-7XXX series alloys [2-4]. FSW is a complex thermomechanical process for which the final microstructure and the mechanical properties of the joint are closely related to tool shoulder/pin geometries and process parameters $[5,6]$. Numerous studies have been conducted to document the effect of welding parameters on the microstructure evolution during FSW and their effect on the mechanical properties of the weld [7-10]. However, the local mechanical response of the joint and the associated stress-strain heterogeneities have been sparsely documented [11-13].

In particular, banded macrostructures were reported in FSW joint and their effect on the local mechanical response of the weld is unclear. These banded macrostructures are common features within FSW joint of similar or dissimilar alloys and are found in a wide range of materials and welding parameters [14-24]. In fact, during FSW process, the metal is subjected to a complex material flow which can lead to heterogeneous microstructures. The material flow is drived by the combined effect of circumvent, circulation, torsion, and vortex due to the material/pin friction. The deformation history of these regions is usely associated to a local extrusion type of process [16-18,20,23,24], but the intensity or the rate at which this extrusion is undergoing depends on the relative position of the material to the pin. For some process parameters, these banded macrostructures appear on macrographs as "onion rings" in the nugget zone when the joint is cut normally to the welding direction. The formation of these bands results from periodical layered material flow in the vinicity of the tool; each band experiencing different strain rate gradient, total equivalent plastic strain, and maximum temperature during one tool revolution. The variations in the strain rate gradient is correlated with tool geometry $[23,24]$ and tool eccentricity [23] during the welding process. Threadgill [14] first related the spacing between adjacent bands and the tool advance per revolution by looking at the joint along the welding direction. This was later confirmed by various authors [15,25]. More recently, a secondary periodicity was observed on non-axisymmetric tools (trigonal and tetragonal tools) and associated to the stack of material on each face of the tool during tool revolution $[23,24]$.

The effect of the banded macrostructures on the local microstructure and mechanical properties of the FSW joint has been discussed in recent studies [11-13,16,18,20]. Schneider et al. [16] reported an evolution in crystallographic textures from band to band and correlate it with dynamic recrystallization. This periodic variation in texture was further confirmed by Fonda et al. [18] and Xu [20]. Moreover, Mahoney et al. [26] showed that the fracture path tends to develop along periodic bands under monotonic tensile loading. On the mechanical point of view, Sutton et al. $[11,12]$ reported the heterogeneous mechanical response of a joint presenting banded macrostructures. They have associated hardness and local strain variations in the joint to variations in grain size and particle distribution within the banded macrostructures. Sutton et al. [11] and more recently, Dhondt et al. [13] evidenced by digital image correlation (DIC) the periodicity of the local tensile properties along the welding direction in the mid-plane of similar AA-2XXX-T3 FSW joints and have associated some periodicity with the presence of banded macrostructures.

In order to further understand the relationship between the local macrostructure of a FSW joint and its mechanical properties, the present work has investigated the influence of material flow on the mechanical properties in the weld region affected by the tool shoulder in a dissimilar FSW joint between a AA-2024 and a AA-2198. A particular attention was paid to the shoulder-affected region of the joint as the friction of the shoulder and the pin with the plates in this region result in complex micro-/macrostructure heterogeneities. The crown side region of a dissimilar weld joint was observed through optical high resolution-digital image correlation technique (OHR-DIC) during monotonic tensile test. Hardness measurements and electron backscattered diffraction analyses (EBSD) were also run to further document the heterogeneities in this region of the weld. The effect of the complex
3D micro and macrostructure structure of the joint on the local and global mechanical properties of the joint is discussed.

\section{Materials and experimental procedures}

\subsection{Materials}

A dissimilar AA-2024/AA-2198 butt joint was obtained by FSW process with $\mathrm{RD} / \mathrm{TD}$ sheet configuration as reported in detail in a previous study [27]. Base material was supplied as $3.18 \mathrm{~mm}$ thick sheets in a T3 temper condition, in which the material is solution heat-treated, stretched, and naturally aged. In this study, AA-2024-T3 and AA-2198T3 sheets are on retreating side (RS) and advancing side (AS), respectively. The welding direction (WD) is parallel to the AA-2024 rolling direction (RD) and perpendicular to the AA-2198 RD direction (Fig. 1). This configuration was chosen to allow the AA-2024-T3 and AA-2198T3 base material to display very comparable uniaxial tensile properties along the loading directions [27]. For convenience, the transverse direction of the joint will be denoted cross-welding direction (CWD) in this article. The welded sheets were stored for one year at room temperature after welding to ensure a stabilized natural ageing microstructure. As proposed in reference [27], a color code is used in the present study to identify the various regions in the joint, i.e. the thermomechanical affected zone (TMAZ) and the nugget for both materials as specified in the Fig. 1. For the proper characterization of the joint, a $150 \mu$ m-thick layer of material was removed from the surface in order to prevent surface striations inherent to the FSW process to alter characterizations (crown side - see colored CWD-WD plane in Fig. 1) by generating stress concentration marks. The CWD-WD plane located $150 \mu \mathrm{m}$ beneath the crown side of the joint is referred as the "Top surface" in the present paper.

\subsection{Macrostructure characterization}

In order to investigate the evolution of the microstructure across the joint on CWD-WD planes in the first hundreds of micrometers regions beneath the crown side (Fig. 1), a serial-section polishing procedure was used. A $22 \times 5 \mathrm{~mm}^{2}$ rectangular specimen, sampling the entire joint, was used for this purpose. For each section step, the sample was polished with a tripod polisher down to $1 \mu \mathrm{m}$ diamond particles. A final chemical-mechanically polishing with $0.05 \mu \mathrm{m}$ colloidal silica was performed for $12 \mathrm{~h}$ with a BUEHLER Vibrometer. This conventional metallographic technique was also used for preparing samples dedicated to

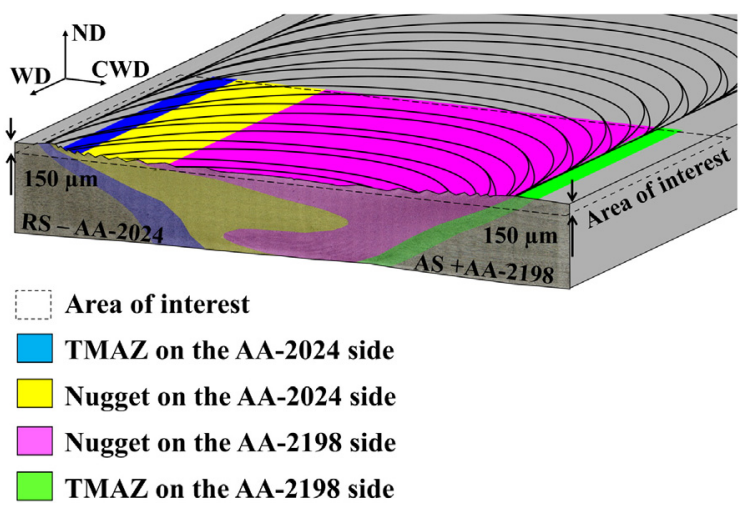

Fig. 1. Sheet configuration for the friction stir weld of dissimilar AA-2198/AA-2024 alloys (WD: welding direction, CWD: cross weld direction, ND: normal direction). The CWD-WD plane located $150 \mu \mathrm{m}$ beneath the top surface corresponds to the area of interest in the present work. Different color codes were used for a better identification of the TMAZ and the Nugget for both the aluminum alloys in the web version of this article. (For interpretation of the references to color in this figure legend, the reader is referred to the web version of this article.) 
electron backscatter diffraction (EBSD) and microhardness measurements. Specimens were finally etched with a Keller solution ( $2 \mathrm{~mL} \mathrm{HF}$, $3 \mathrm{~mL} \mathrm{HCl}, 5 \mathrm{~mL} \mathrm{HNO}_{3}, 190 \mathrm{~mL} \mathrm{H}_{2} \mathrm{O}$ ) at $25^{\circ} \mathrm{C}$ during $7 \mathrm{~s}$ to reveal the microstructure. Optical observations were conducted with an OLYMPUS DSX500 optical-digital microscope in bright-field mode. This procedure was conducted for various sectioning steps in the first $700 \mu \mathrm{m}$ beneath the Top surface; the step size between each section was $50 \pm 5 \mu \mathrm{m}$ in depth.

\subsection{Texture analysis}

EBSD measurements were performed on the Top surface CWD-WD plane in a Hitachi SU-70 SEM operating at $15 \mathrm{kV}$ and at typical current of $1.5 \mathrm{nA}$. Orientation maps were obtained using the HKL Channel 5 acquisition system of Oxford instruments. Large area and local area EBSD scans were conducted to investigate both the texture and the grain microstructure, respectively. Large area scans sampling a $2 \mathrm{~mm}^{2}$ region with $2 \mu \mathrm{m}$ step size were run together with local scan covering $0.15 \mathrm{~mm}^{2}$ with $0.5 \mu \mathrm{m}$ step size. Fiducial markers were used to correlate EBSD scans with optical observations.

\subsection{Micro-hardness measurements}

Vickers hardness maps were measured with a CLEMEX machine with a $25 \mathrm{gf}$ load applied for $10 \mathrm{~s}$ to analyze the hardness distribution across the Top surface WD-CWD plane. At 25 gf, the indent diagonal is typically about four times the average grain size diameter in the nugget. 30 profiles of 205 indents have been made according to a regularly spaced square pattern $(80 \mu \mathrm{m})$. The total area covered by the microharness mapping was $16.4 \times 2.3 \mathrm{~mm}^{2}$. Subsequent to the hardness measurements, the specimen was etched (see Section 2.2) to accurately correlate the location of each indent to the banded macrostructures.

\subsection{Tensile specimen preparation}

Dog-bone tensile specimens were machined out by CNC milling from the welded plates in the cross-welding direction (CWD). A $30 \mathrm{~mm}$ long gage was chosen to sample the typical regions of the joint, i.e. the base metal (BM), the heat affected zone (HAZ), the thermomechanical heat affected zone (TMAZ), and the nugget zone (NZ). The butt weld was centered in the gage section and the loading axis was normal to the welding direction (WD). Schematic of the tensile specimens is given in Fig. 2. As for the microhardness measurements and EBSD analyses, surface striations inherent to the FSW process were first removed by polishing a $150 \mu \mathrm{m}$ trench on the crown side of the joint, i.e. down to the Top surface CWD-WD plane. Specimens were then polished from the root side to obtain specimen from the top region of the weld only. As the shoulder-affected region is comprised in a region about half a millimeter [27], $700 \mu \mathrm{m}$ thick specimens were prepared out of the $3.18 \mathrm{~mm}$ thick sheet by polishing using a Tripod polisher. A $4000 \mathrm{SiC}$ grit paper was used to prepare the both specimen faces prior to tensile deformation. Specimens were etched with a Keller solution to produce a sub-grain scale speckle pattern which happens to be favorable for digital image correlation. (a)

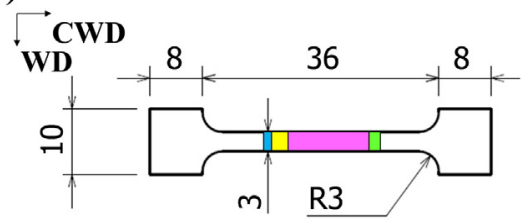

(b)

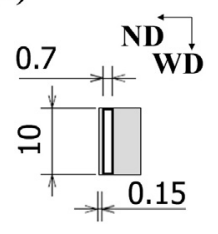

Fig. 2. Specimen geometry of the tensile specimens represented in (a) CWD-WD and (b) ND-WD planes (in $\mathrm{mm}$ ).

\section{(a)}

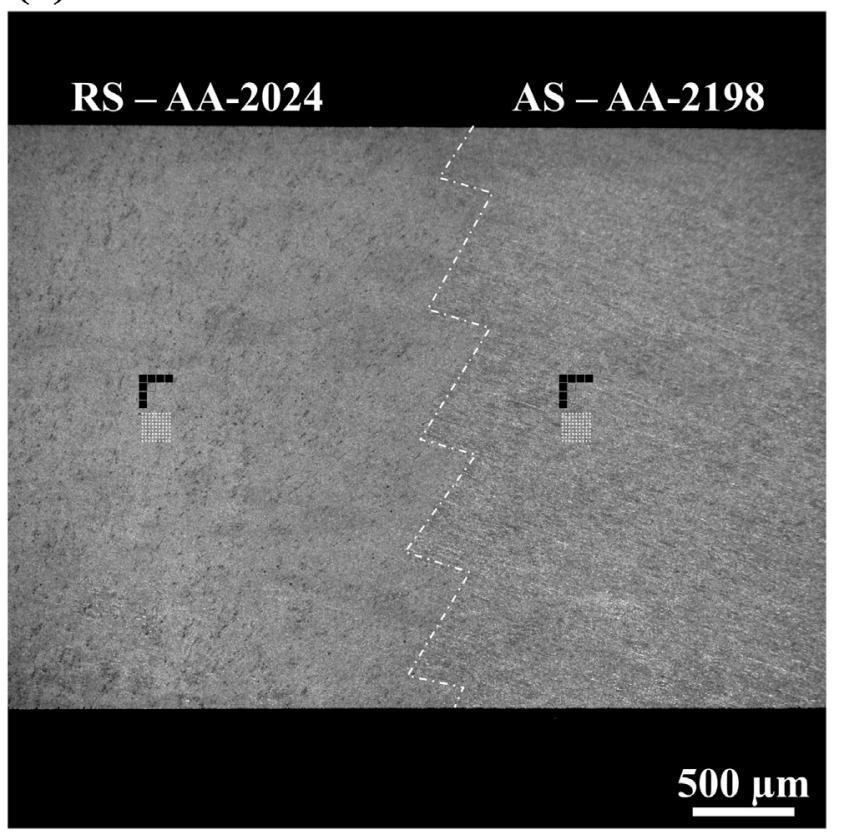

(b)
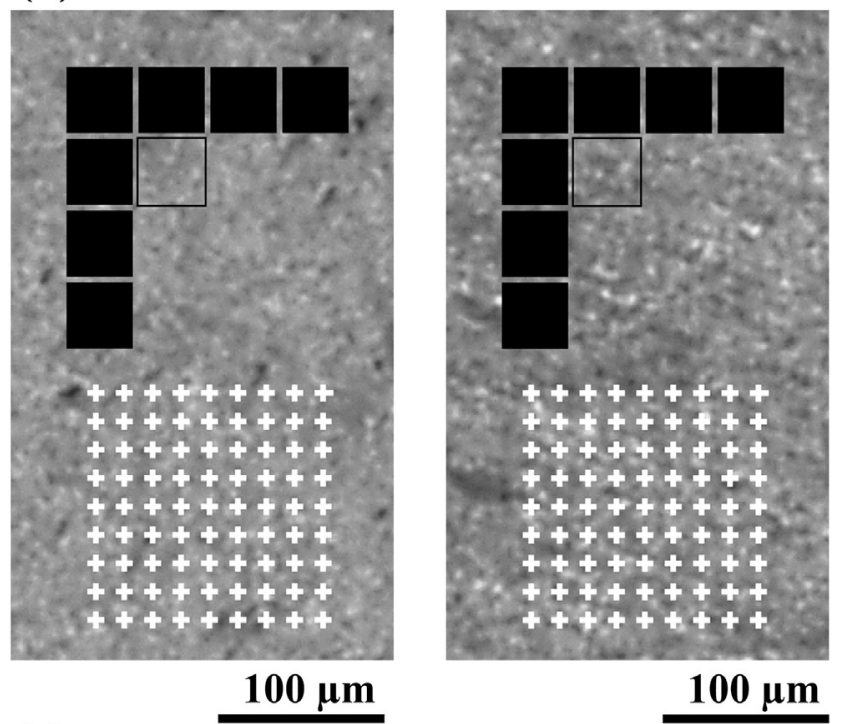

$100 \mu \mathrm{m}$

(c)
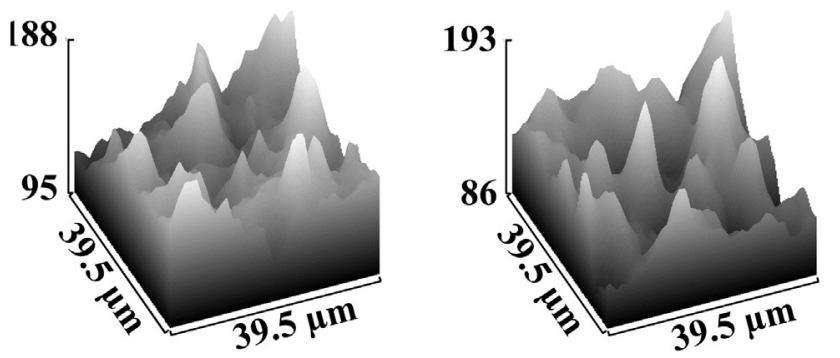

Fig. 3. (a) Optical micrograph of the specimen at the AA-2024/AA-2198 junction in the nugget region on a dark field observation mode. The white dashed line represent the AA-2024/AA-2198 junction (b) Expanded views of both the AA-2024 (left) and the AA-2198 (right) to depict the speckle. Black boxes and white crosses correspond to the subset size and the measurement grid used for the DIC technique. (c) 3D representation of a typical subset gray level of both the AA-2024 (left) and the AA-2198 (right) to show the relatively high number of local minima/maxima necessary for the ZNCC criterioncalculation. 


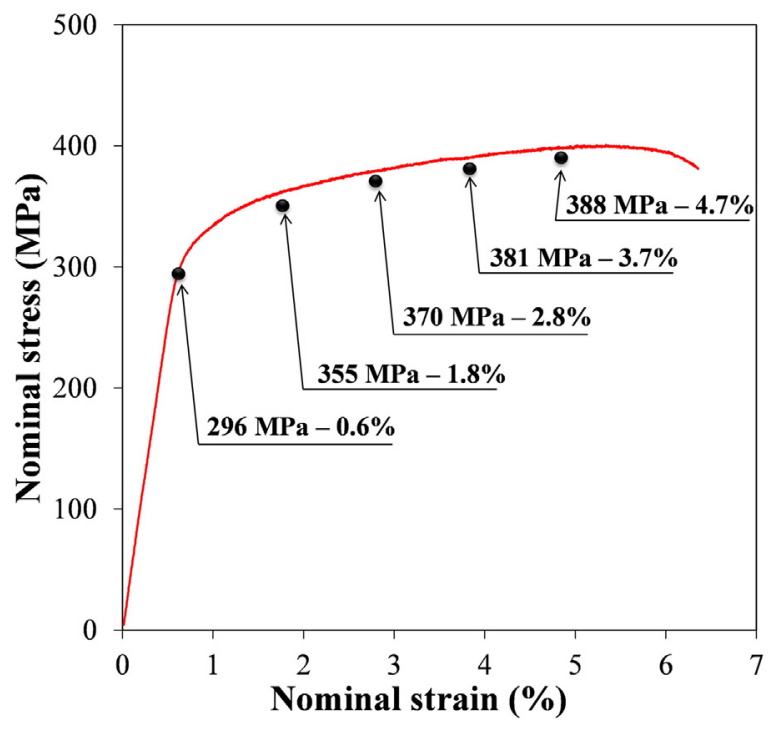

Fig. 4. Macroscopic stress-strain behavior corresponding to the shoulder-affected region of the joint and the macroscopic strains measured by crosshead displacements at the various holding stress for which OHR-DIC measurements were made (black dots).

Observation in a dark-field mode aims to highlight sub-micron surface defects and to overcome the strong brightness/contrast noticeable in dissimilar joints with direct illumination techniques. Fig. 3 images the typical speckles obtained for the AA-2024 and the AA-2198 materials with an optical microscope.

2.6. Monotonic tensile tests and optical high resolution-digital image correlation (OHR-DIC) experiments

Monotonic tensile tests were performed on a $5 \mathrm{kN}$ micro-tensile machine (Kammrath \& Weiss) under displacement control (strain rate of approximately $2.3 \times 10^{-4} \mathrm{~s}^{-1}$ ). Grips displacement was continuously recorded with a $1 \mu \mathrm{m}$-resolution that allows assessing the macroscopic stress-strain behavior under monotonic tensile stresses. The compliance of the tensile device was previously measured by using a contact extensometer on two specimens to obtain macroscopic strain from grips displacement (Fig. 4).
Optical microscope images were simultaneously recorded to perform strain measurements by OHR-DIC. As explained in [28-30], DIC is a full-field image analysis technique that aims to compare images at different macroscopic stress or strain levels to reference images. Inplane displacements were calculated with OpenDIC [28], an open source software whose correlation techniques are based on the zero-normalized cross-correlation criterion in an incremental mode. As OpenDIC software does not make any assumption of average strain fields, heterogeneous and discontinuous displacements can be accurately documented. This correlation technique had demonstrated a high precision and robustness of the measurements, especially with respect to illumination variations and speckle evolutions inherent to the high deformation levels that can be generated at the local scale [28-30]. The in-plane local strain field was finally calculated from the displacement field obtained from images correlation via a Matlab ${ }^{\circledR}$ companion application. $\varepsilon_{\mathrm{XX}}, \varepsilon_{\mathrm{YY}}$, and $\varepsilon_{\mathrm{XY}}$ maps were generated via an isoparametric 2-D finite element formalism using subset centers as nodes and four Gauss bilinear interpolation points per element. No further smoothing or filtering was applied in order to document precisely the heterogeneous nature of the deformation.

Digital images ( $3594 * 3594$ pixels) were acquired with an OLYMPUS DSX500 optical-digital microscope with a MPLFLNX5BDP objective lens ( $5 \times$ magnification) to obtain $1.13 \mu \mathrm{m}$ image resolution. The microscope was positioned normal to the specimen surface (WD-CWD plane) with the horizontal direction of each images corresponding to the loading direction. Series of reference images were acquired for each specimen. Reference pictures were taken after the griping of the specimen in the micro-tensile and stage set under zero load. Other series of deformed pictures were taken at various straining conditions corresponding to: $92 \%$ of the $0.2 \%$ strain offset macroscopic yielding (Y.S.), and regularly spaced plastic strain levels from $1.2 \%$ to $4.1 \%$ plastic strain (Fig. 4). Strain field calculations were distinctly conducted on each area for the various stress/strain levels then stitched together to obtain the large $\varepsilon_{X X}, \varepsilon_{Y Y}$, and $\varepsilon_{X Y}$ maps [31].

The size of the subsets and step was chosen as $35 \times 35$ pixels $(39.5 \times 39.5 \mu \mathrm{m}[2])$ and 15 pixels $(16.9 \mu \mathrm{m})$, respectively. Calculation was performed with an interpolation factor of 16 using a biquintic polynomial algorithm giving a theoretical accuracy of $71 \mathrm{~nm}$ in displacement. Typical subset and step size are reported in Fig. 3, using black boxes and white crosses grid, respectively. Fig. 3.c evidences the significant contrast and large number of local minima/maxima per subset, which allow singular speckle to be obtained for each subset and high zero-normalized cross-correlation values.

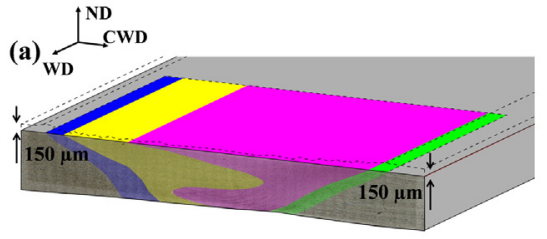

(b)

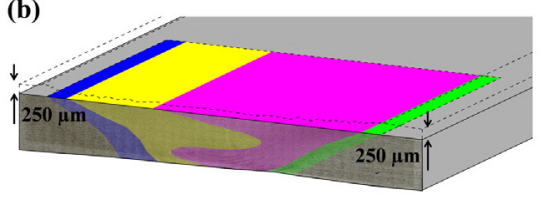

(c)

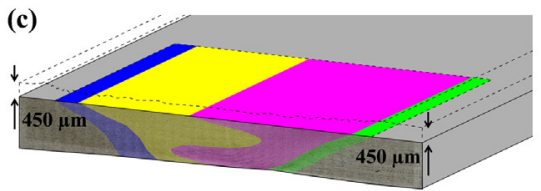

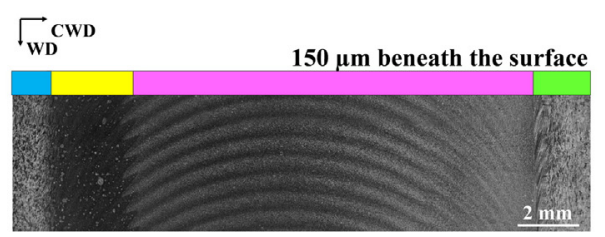

$250 \mu \mathrm{m}$ beneath the surface

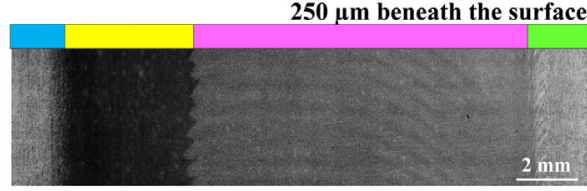

TMAZ on the AA-2024 side

Nugget on the AA-2024 side

Nugget on the AA-2198 side

TMAZ on the AA-2198 side

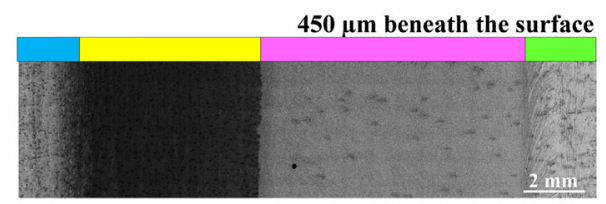

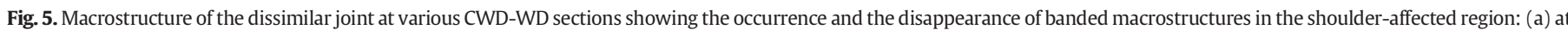
$150 \mu \mathrm{m}$ beneath the top surface, (b) at $250 \mu \mathrm{m}$ beneath the top surface, (c) at $450 \mu \mathrm{m}$ beneath the top surface. 


\section{Results}

\subsection{Macrostructure characterization}

The detailed microstructure characterization of the dissimilar joint under investigation in the present paper is reported in Ref. [27]. In the present study, only the shoulder-affected region of the joint is further detailed. That corresponds to the 700 hundreds micrometers deep region under the Top surface CWD-WD plane. Two regions of the banded macrostructures within the nugget region on the AA-2198 side are documented in Fig. 5.a and b along CWD-WD sections. Interestingly, the gray-level contrast between banded macrostructures is relatively pronounced in the first step of material removal (Fig. 5.a) and tends to disappear as the depth increases (Fig. 5.b and c). The distance between bands along WD is equal to the tool advance per tool revolution. At $450 \mu \mathrm{m}$ beneath the crown side, the macrostructure of the nugget region on the AA-2198 side presents relatively homogeneous microstructure and no banded macrostructure can be found (Fig. 5.c).

The 3D description of the AA-2024/AA-2198 interface is relatively complex. First, this bi-metal interface demonstrates a particularly sharp saw-teeth pattern at the Top surface section of the joint (Fig. 5.a) and a smoother interface in subjacent sections (Fig. 5.c), where no banded macrostructures were found. The saw-teeth pattern of the bi-metal interface, together with the spatial period equal to the tool advance per tool revolution, testified the required variation in total equivalent plastic strain during one rotation of the tool for the formation of banded macrostructures. In addition, the position of the bi-metal interface changes from one CWD-WD section to the next. In this range of depth, the bi-metal interface evolves significantly from the retreating side to the advancing side, especially when moving towards the root side, as depicted in Fig. 5. This observation is in accordance with the relatively low-angle slope made by the bi-metal interface within the nugget region depicted on cross-section observations (see e.g. CWD-ND plane in Fig. 1 and ref. [27]). This observation is particularly relevant due to the potential effect of material behavior underneath the studied "surface" (microhardness versus OHR-DIC).

\subsection{Texture analysis on the CWD-WD plane}

Three areas within the nugget region were analyzed by EBSD measurements on the Top surface CWD-WD section (Top right inserts in Fig. 6). The areas displayed as 1, 2, and 3 in Fig. 6.a correspond to the nugget regions located at $1 \mathrm{~mm}$ (AS $+1 \mathrm{~mm}), 5 \mathrm{~mm}(A S+5 \mathrm{~mm})$, and $7 \mathrm{~mm}$ (AS $+7 \mathrm{~mm}$ ) from the joint centerline on the advancing side, respectively (Fig. 6.b and c). Inverse pole figure (IPF) maps were displayed according to two morphological directions of the bands (the elongation and the normal direction of the bands depicted as black arrows). Two fibers are noticed on the orientation maps when using the color IPF that corresponds to local material flow. Pronounced variations in local texture were thus found from band to band.

Textures were also highlighted in the pole figures represented in Fig. 6.d for the different investigated regions depicted in Fig. 6.a. The white arrows depicted in the $\{111\}$ and $\{110\}$ pole figures in Fig. 6.d correspond to the material flow direction and its normal direction, respectively. The highest pole intensities were found for the $\langle 111\rangle$ crystallographic orientations aligned with the direction normal to the material flow direction (blue regions in Fig. 6.c). These highest pole intensities are related to the great occurrence of the $\mathrm{B} / \overline{\mathrm{B}}((111)[1 \overline{1} 0] /$ (111) $[0 \overline{1} 1])$ texture components of the $\gamma$ fiber, demonstrating the importance of shearing and recrystallization process in this region of the joint. On the other hand, $\{110\}$ pole figures display $\langle 110\rangle$ texture fibers along the material flow direction (green regions in Fig. 6.b). Between the large and pronounced $\langle 110\rangle$ fiber bands related to the material flow direction (displayed in green in Fig. 6.b), a less pronounced texture fiber is observed (displayed as pinkish in Fig. 6.b and as a pinkish/green mixture in Fig. 6.c). These less pronounced fibers highlight the presence of $A / C((112)[1 \overline{1} 0] /(110)[1 \overline{1} 0])$ texture components typical of the $\alpha$ fiber, typical of high shearing processes. These observed fiber texture regions (a)

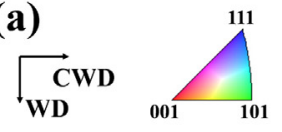

(b)

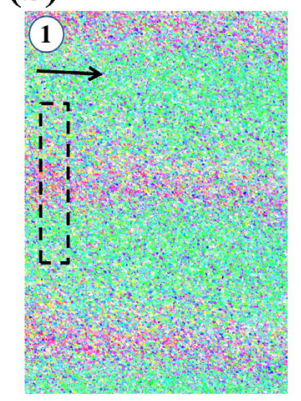

(c)

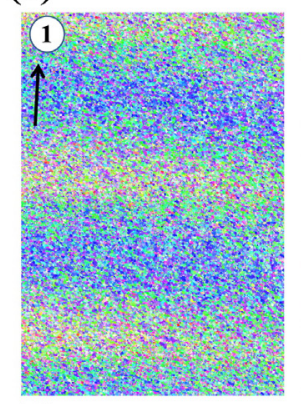

(d)
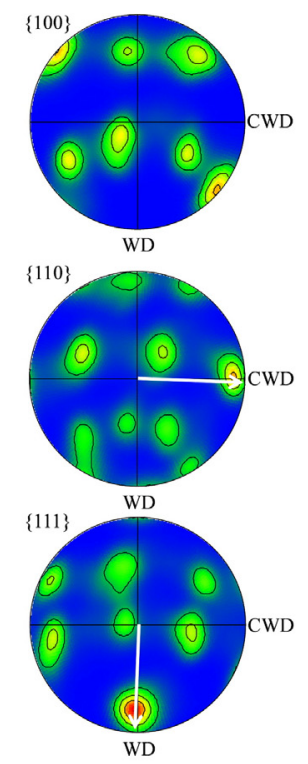

0
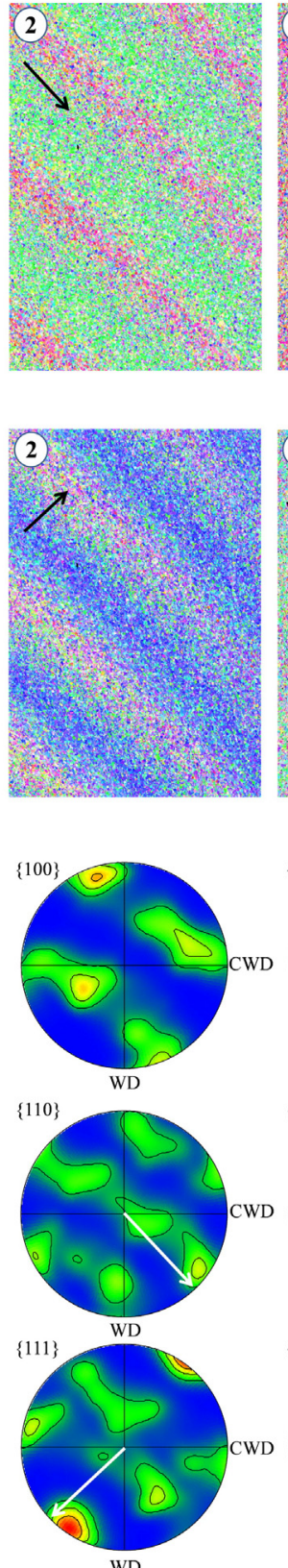

0
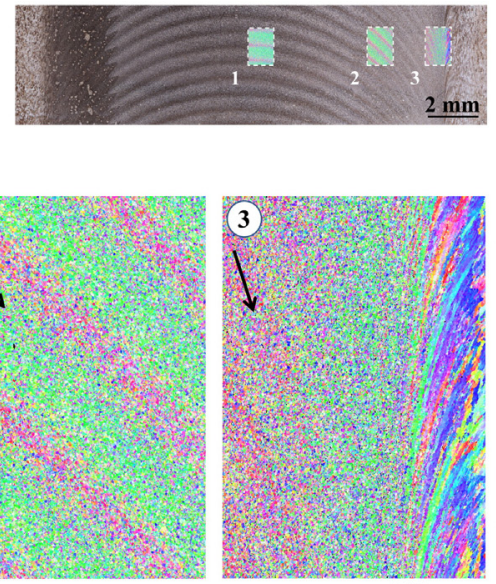

$250 \mu \mathrm{m}$

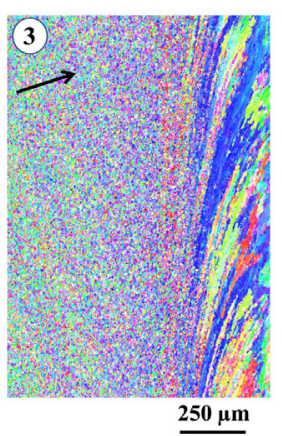

$\underline{250 \mu \mathrm{m}}$
Fig. 6. (a) Position of three regions in the joint numbered 1 to 3 located on the advancing side in a CWD-WD section at $150 \mu \mathrm{m}$ beneath the top surface. They were taken respectively at AS $+1 \mathrm{~mm}$, AS $+5 \mathrm{~mm}$ and $\mathrm{AS}+7 \mathrm{~mm}$. Inverse pole figures (IPF) maps showing the intimate relationship between (b) the material flow direction and (c) the direction normal to the material flow (illustrated as black arrows) and the local texture. (d) $\{100\},\{110\}$ and $\{111\}$ contoured pole figures of the all maps confirming strong crystallographic textures. $\langle 110\rangle$ and $\langle 111\rangle$ preferential orientations were aligned with the material flow direction and the direction normal to the material flow, respectively, depicted as white arrows. The dashed region in Fig. 1.b Region 1 corresponds to the map investigated in Fig. 7. 
are denoted "green bands" and "pink bands" in the following text for reading conveniences. Interestingly, the "green" and "pink" bands were found to correlate perfectly with the light gray bands and dark gray bands shown in the optical image in Fig. 5.a.

High resolution EBSD scans were performed on a region at AS $+1 \mathrm{~mm}$ to better assess the evolution of the crystallographic orientation from one band to the next. Fig. 7 displays such a high resolution map with a color code related to the CWD direction, being nearly parallel to the morphological direction of the bands. The grain sizes and morphologies were found to be similar in both texture fibers.
Various IPFs were added to the figure to document the texture variation along the periodic banded macrostructures using related multiple of uniform distribution (MUD) factor according to the CWD and WD directions. In this figure, the red and blue lines (dark and light gray in the black and white version) in the scale bars display for each region the maximum of the MUD according to the CWD and WD directions, respectively. A more pronounced texture was found in the "green" bands than in the "pink" bands. Moreover, the texture intensity evolves across a single band, reaching a maximum at the center of the "green band". Grains in the "green" bands are favorably oriented according to
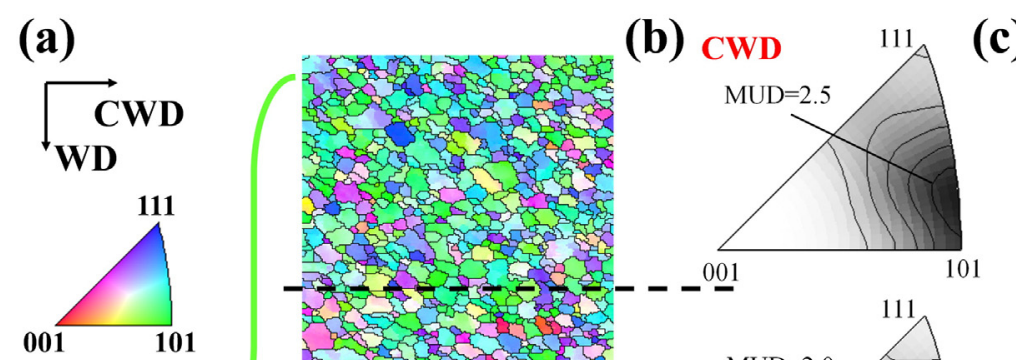

(c) $\mathrm{WD}$

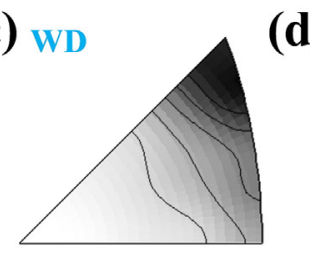

(d)

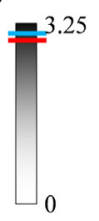
(1)
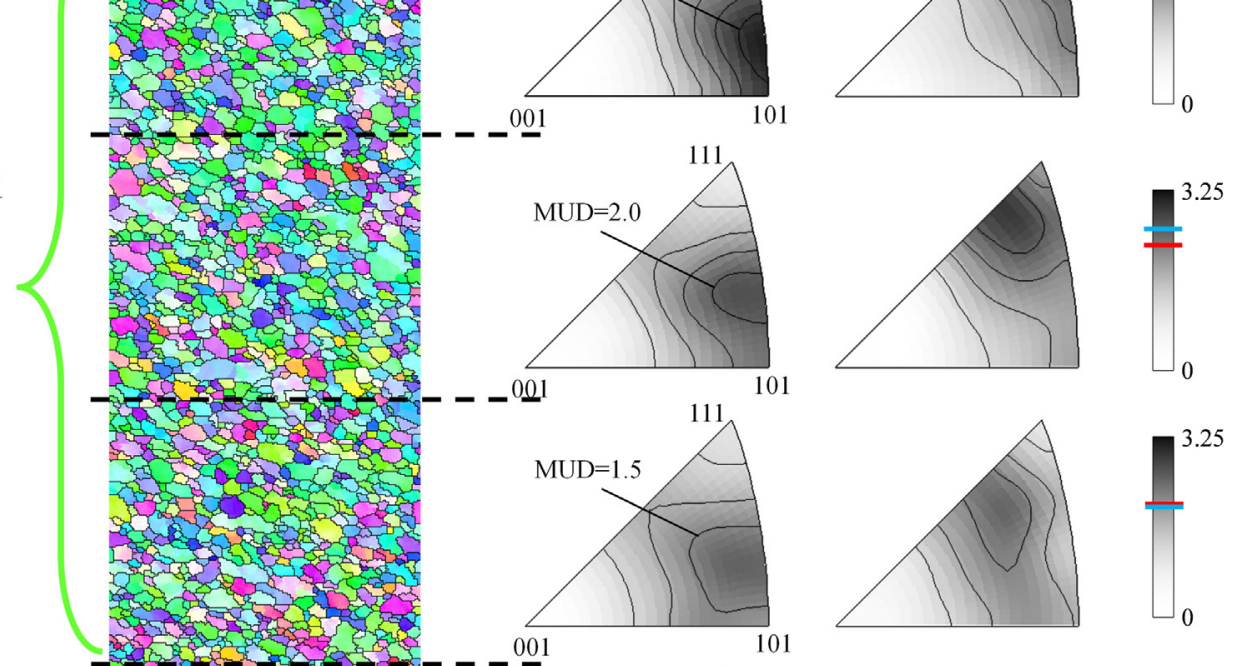

$-001$

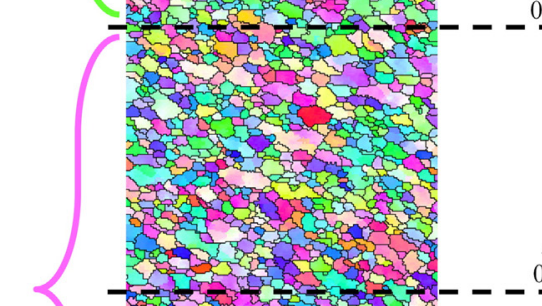

-001
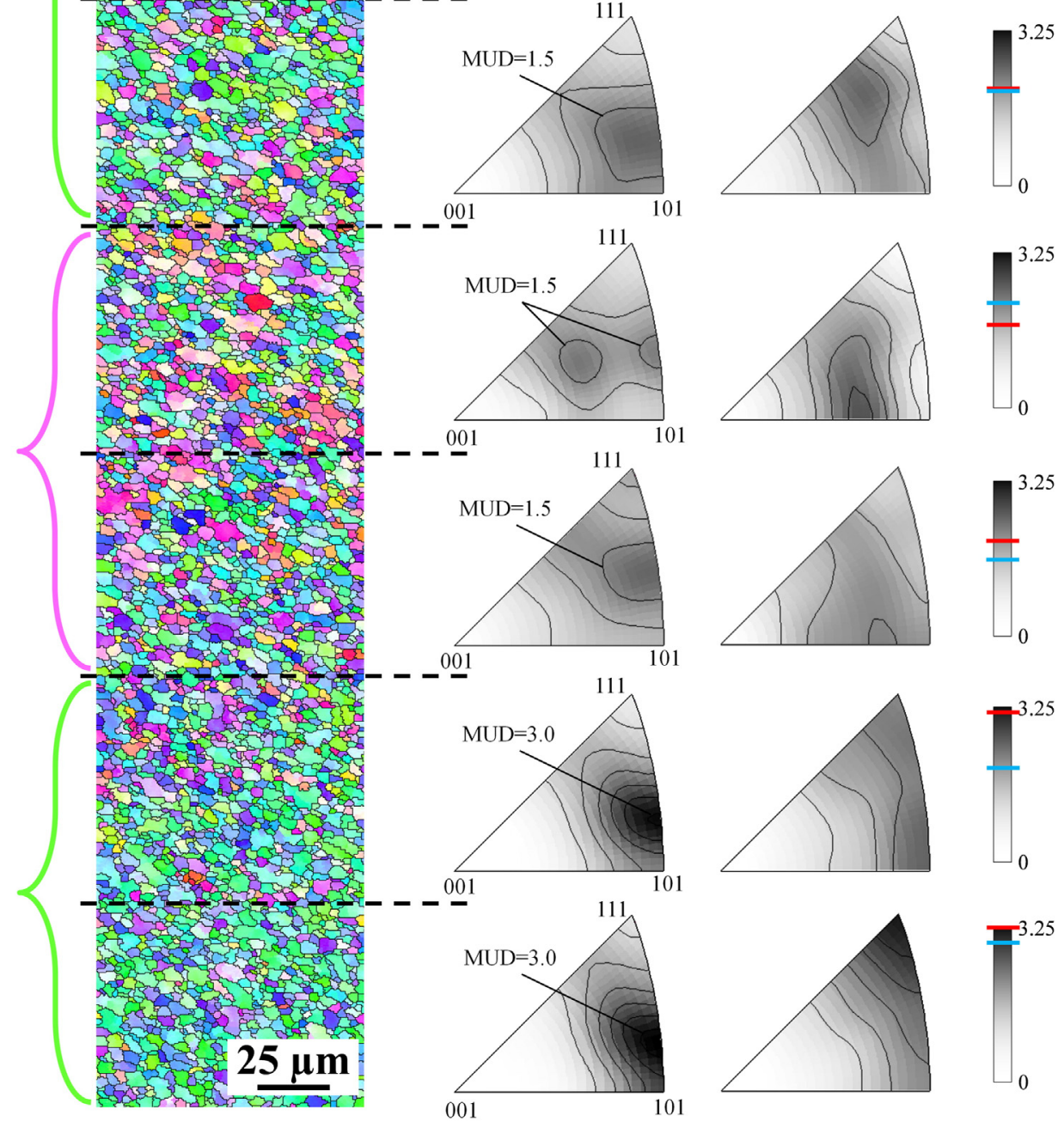

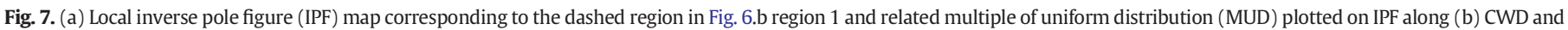

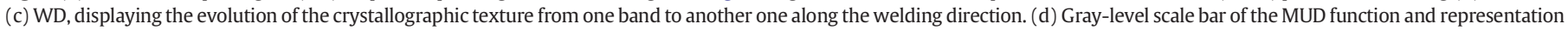

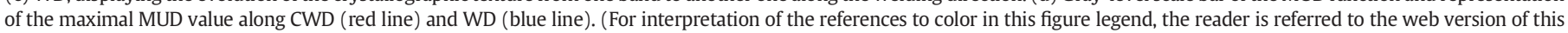
article.) 
the material flow direction along the $\langle 110\rangle$ direction. On the other hand, grains in the "pink" bands are more randomly orientated.

\subsection{Hardness behavior in the CWD-WD plane}

Micro-hardness measurements performed in the Top surface WDCWD section are presented in Fig. 8. In general, AA-2024-T3 demonstrates significantly higher hardness than AA-2198-T3, both in the base metal $\left(\Delta \mathrm{HV}_{0.25}=25\right)$ and in the nugget regions $\left(\Delta \mathrm{HV}_{0.25}=27\right)$. The TMAZ regions have shown to be stronger than the nugget region on the AA-2024 side (retreating side - RS) and weaker on the AA2198 side (advancing side - AS). Average hardness values along the CWD direction were calculated by integrating the entire measurements for a given coordinate (solid black plot in Fig. 8.b). Three minima were observed along the joint respectively at RS-4.5 mm (115 HV), at AS $+3.9 \mathrm{~mm}(114 \mathrm{HV})$, and at AS $+8.2 \mathrm{~mm}(113 \mathrm{HV})$. The minimal hardness is located on the advancing side in the TMAZ region, which is out of the nugget region.

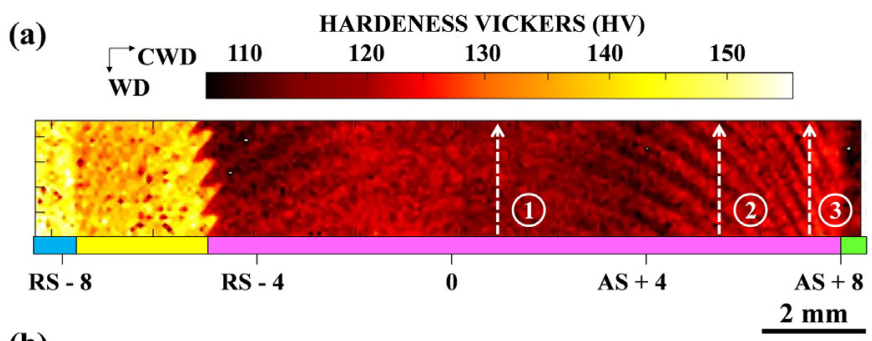

(b)
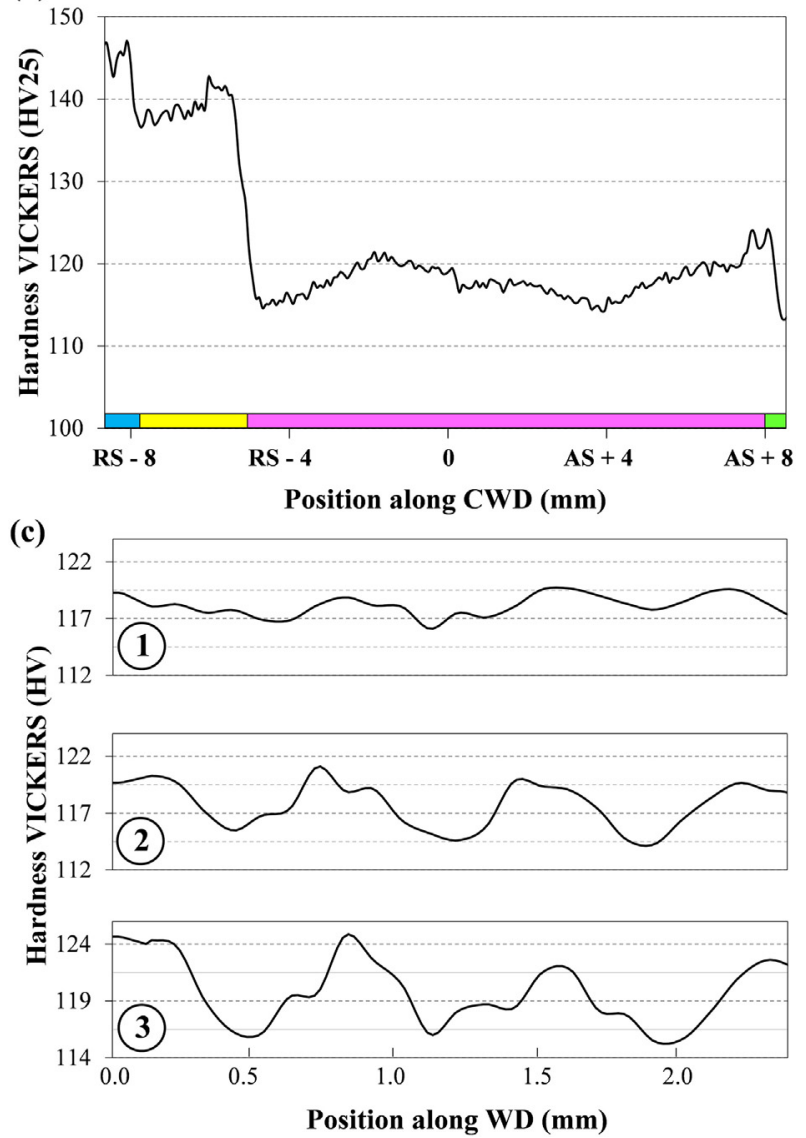

Fig. 8. (a) Hardness map across the WD-CWD plane located $150 \mu \mathrm{m}$ beneath the top surface. (b) Mean hardness values along CWD (The mean hardness value is calculated by integrating the entire measurements for a given coordinate). (c) Mean hardness values along WD for three locations in the AA-2198 nugget region corresponding to the dashed white lines in Fig. 8 .a obtained at AS $+1 \mathrm{~mm}$, AS $+5 \mathrm{~mm}$ and AS $+7 \mathrm{~mm}$.
In the nugget, the AA-2024 region exhibits relatively homogeneous hardness properties whereas significant variations were noticed on the AA-2198 side. High hardness bands (HHB) and low hardness bands (LHB) and were found at some distance from the joint center. These bands were found on both sizes of the nugget (i.e., the advancing and the retreating sides) in regions with the AA-2198 alloy composition. It was also found that the LHB and HHB correspond respectively to the light gray and dark gray bands observed on the optical micrograph in Fig. 5 ("green" and "pink" bands in the crystalline texture context).

More specifically, some hardness profiles are presented in Fig. 8.c for three lines along WD as depicted by dashed white lines in Fig. 8.a. This better documents the periodicity in hardness along WD in the banded macrostructures. Periodical deviations from the mean hardness value were noticed for the three locations. The magnitude of these deviations progressively increases farther away from the centerline of the joint indicating the stronger difference in hardness between LHBs and HHBs when moving away from the centerline.

\subsection{Local monotonic tensile behavior from DIC measurements}

The Top surface of the specimen (CWD-WD plane) was used to perform OHR-DIC measurements. As specified earlier, tensile tests were conducted at room temperature on $700 \mu \mathrm{m}$-thick tensile specimens extracted from the shoulder-affected region of the joint. A first series of two tests was conducted to measure macroscopic properties. The typical strain stress curve is shown in Fig. 4. A 0.2\% offset yield strength (Y.S.) of $325 \pm 2 \mathrm{MPa}$ and an ultimate tensile strength (U.T.S.) of $400 \pm 1 \mathrm{MPa}$ at $4.9 \%$ plastic strain were obtained. The stress progressively dropped for strain applied above U.T.S. due to a significant necking effect at AS $+6 \mathrm{~mm}$, where the final fracture of the samples systematically takes place.

Five loading steps in elastic and plastic regimes on a single specimen were investigated by DIC measurements. No time-dependent deformation was noticed during data acquisition thanks to the relative short acquisition time per micrograph. The black dots depicted in Fig. 4 correspond to the average value of the principal strain obtained with DIC measurements for each straining conditions. The two sets of data are coherent and prove that the strain maps obtain by DIC can be exploited. The $\varepsilon_{X X}, \varepsilon_{Y Y}$ and $\varepsilon_{X Y}$ strain fields (X and Y directions correspond to CWD and WD, respectively) from OHR-DIC measurements are actually displayed in Fig. 9. The deformations are not symmetrical and the behavior of the AA-2198 nugget region in the retreating side differs from the one in the advancing side. Even at early deformation steps, the $\varepsilon_{X X}$ strain fields show significant strain localization where the final fracture will occur; i.e., in the nugget close to the TMAZ region at AS $+6 \mathrm{~mm}$. The local deformations were found to be up to five times higher than the macroscopic strain.

High deformation bands (HDB) and low deformation bands (LDB) were observed on the strain maps in the region known to display the banded macrostructures (identified in the optical image in Fig. 5.a as light gray and dark gray band, respectively) and explain some characteristics related to the strain localization. The average $\varepsilon_{X X}$ and $\varepsilon_{Y Y}$ values for a given distance from the joint center were plotted as a function of the CWD coordinated in Fig. 10 for various strain levels. At a low applied strain, Fig. 10.a confirmed that strain localization occurred first between AS $+3 \mathrm{~mm}$ and AS $+7 \mathrm{~mm}$, a maximal $\varepsilon_{\mathrm{xx}}$ value being found close to AS $+6 \mathrm{~mm}$. The remaining region of the joint (from RS- $8 \mathrm{~mm}$ to AS $+3 \mathrm{~mm}$ ) exhibited a uniform low (elastic) strain level similar to the one found in base materials. When increasing the macroscopic strain level, the local deformation remains mainly localized at AS $+6 \mathrm{~mm}$ (Fig. 10.b and c).

As depicted in Fig. 9, the $\varepsilon_{\mathrm{XX}}$ strain amplitude variation from band to band in the nugget on the AA-2198 side decreases along the CWD direction when moving from the advancing side to the retreating side. Interestingly, the $\varepsilon_{\mathrm{Xx}}$ response remains particularly homogeneous along WD on the retreating side and on the advancing side up to 

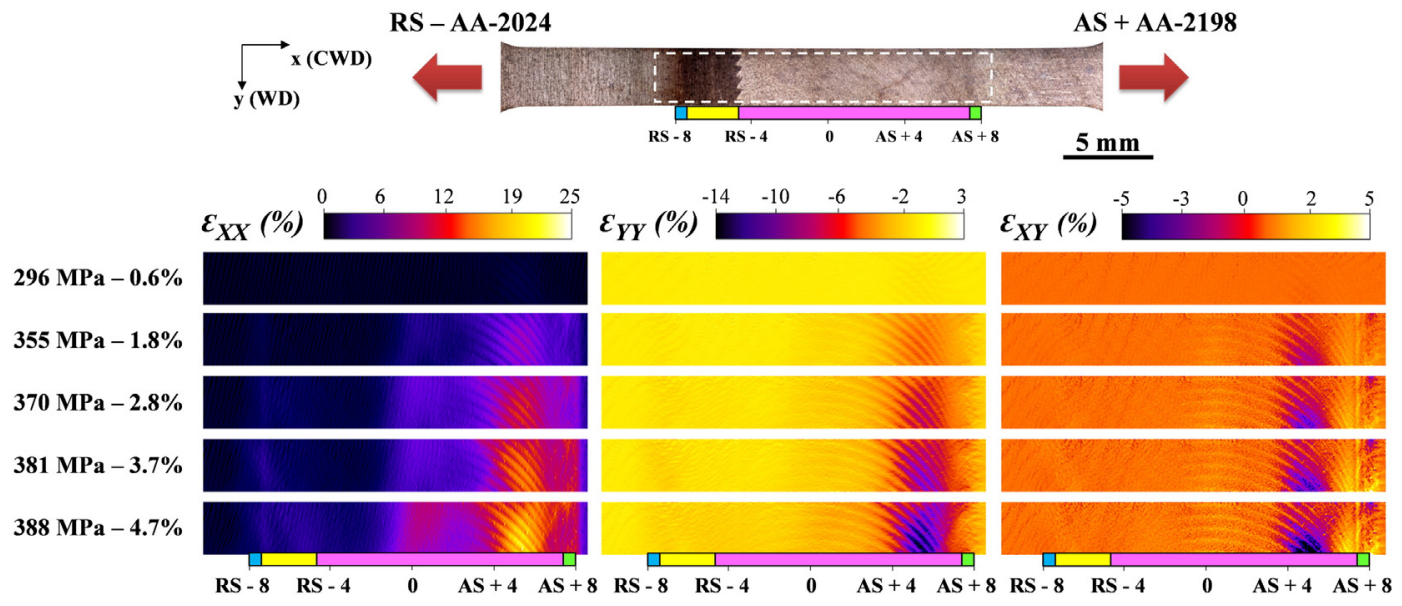

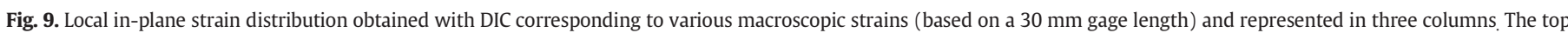
incrustation illustrates the area of interest of the joint used for DIC measurements.

AS $+3 \mathrm{~mm}$, while the HDB/LDB pattern is clearly visible on the $\varepsilon_{Y Y}$ and $\varepsilon_{X Y}$ maps from RS-1 mm to the rest of the advancing side, even in the center of the nugget.

On the other hand, strain profiles along the WD direction plotted in Fig. 11.a to $\mathrm{f}$ for the three sections defined in Fig. 8 (AS $+1 \mathrm{~mm}$, AS $+5 \mathrm{~mm}$, and AS $+7 \mathrm{~mm}$ ) document the significant periodic variations in local strain ( $\varepsilon_{X X}$ and $\varepsilon_{Y Y}$ ) between HDBs and LDBs. As previously noticed, no periodicity is observed on $\varepsilon_{x x}$ strain at AS $+1 \mathrm{~mm}$ (Fig. 11.a) but HDBs and LDBs appears on the $\varepsilon_{Y Y}$ strain maps above macroscopic yielding (Fig. 11.b) with variations of about $\pm 0.18 \%$ and $\pm 0.23 \%$ off the average local $\varepsilon_{\mathrm{YY}}$ strain of $-0.8 \%$ and $-2.4 \%$, for an applied strain of $1.8 \%$ and $4.7 \%$, respectively. It is worth noting that these bands are mostly aligned with the loading direction in this particular region. The amplitude of the variation in strain is maximal in a region between AS $+5 \mathrm{~mm}$ and AS $+7 \mathrm{~mm}$, which is the region where the fracture finally occurred. In the regions AS $+5 \mathrm{~mm}$ and $\mathrm{AS}+7 \mathrm{~mm}$ higher strain values are measured (Fig. 11.c to f) and clear periodicities are observed in both $\varepsilon_{X X}$ and $\varepsilon_{Y Y}$ maps. The morphological direction of the bands is inclined with the loading direction. Local $\varepsilon_{X X}$ strain 1.5 to 3.6 higher than the macroscopic one was reported when the macroscopic strain increase form $1.8 \%$ and $4.7 \%$. Interestingly, some periodicity can already be noticed at $0.92 \%$ of the macroscopic yielding of the specimen, showing that early plastic anisotropic behavior takes place at such a low stress. At AS $+5 \mathrm{~mm}$, variations in strain along WD similar $\varepsilon_{\mathrm{XX}}$ and $\varepsilon_{\mathrm{YY}}$ values are found ( $\pm 1.0 \%$ and $\pm 1.8 \%$ of the average local strain $-5.5 \%$ and $14.9 \%$ - at $1.8 \%$ and $4.7 \%$ macroscopic strain, respectively). It is interesting to note that when $\varepsilon_{X X}$ reaches a maximum value, $\varepsilon_{Y Y}$ reaches a minimum one. At AS $+7 \mathrm{~mm}$, similar results were found but with lower amplitudes.

At high macroscopic strain levels (Fig. 10.b and c), other strain localization regions were found but to a lesser extent than the one documented around AS $+6 \mathrm{~mm}$ : one at the joint center and one at RS-8 mm, this latter region exhibiting relatively poor capability to deform, i.e. maximal hardness values (Fig. 8.b). In addition, the abrupt transition that was found on hardness measurements at the AA-2198/ AA-2024 interface at RS-5 mm is not observed on the strain localizations maps. Interestingly, significant differences were found between the deformation properties obtained by microindentation and the local behavior of the joint as measured under uniaxial tensile loading by OHR-DIC.

\section{Discussions}

Banded macrostructures were found in the top region (shoulderaffected region) of the joint. The local hardness and mechanical response of these banded regions showed that the heterogeneous macrostructure of the joint results in the periodicity of the local mechanical response of the joint material, resulting in high strain localizations in the advancing side of the nugget, where final fracture occurs (Figs. 8 to 12). These banded macrostructures tend to progressively disappear when moving towards the root side of the joint, resulting in a much more homogeneous mechanical behavior in the regions below the surface (Fig. 5). However, the presence of these heterogeneities in the extremely top region of the joint leads to significant strain localizations and control its monotonic fracture.

The periodicity can clearly be related to texture variations within the top nugget region (Figs. 5 to 7). According to the literature, these macroscopic heterogeneities are inherent from the material flow during the FSW process, which comes from the friction between the tool shoulder and the materials and the resulting strain rates gradient [16-18,20, $23,24]$. The banded macrostructures were constituted of alternated $\gamma$ and $\alpha$ texture fibers generated by the material flow. Due to the crystal plastic anisotropy of aluminum alloys [32,33], both fibers are not expected to behave in the same manner under a uniaxial loading. Furthermore, due to the morphological curvature of the bands, the local mechanical solicitation of the $\gamma$ or $\alpha$ texture fibers will differ along CWD, resulting in more or less heterogeneity in their mechanical response. This banded macrostructure can be compared to a composite material with locally "hard" and "soft" bands, leading to strain localization. Such alternation of bands more or less prone to undergo plastic deformation is responsible for mechanical instabilities, early strain localization, and early fracture in heterogeneous materials. In addition, previous DIC measurements performed on the weld cross-section evidenced strain concentrations both in the shoulder-affected region and in the root-side region, in which banded macrostructures were found [27]. The present OHR-DIC measurements have shown the effect of such local heterogeneities on the overall performance of the joint and these results will be discussed further below.

\subsection{Texture in the shoulder-affected region}

EBSD measurements have demonstrated significant variations in local texture from one band to the next as observed in Figs. 6 and 7. The two strong texture fibers, $\gamma$ and $\alpha$ texture fibers, respectively composed mainly of $\mathrm{B} / \overline{\mathrm{B}}((111)[1 \overline{1} 0] /(111)[0 \overline{1} 1])$ and $\mathrm{A} / \mathrm{C}((112)[1 \overline{1} 0] /$ (110) $[1 \overline{10}]$ ) components, were found to develop under the local extrusion process undergoing during the shoulder/tool and material interaction. They are clearly revealed as "green" and "pink" bands in the AS $+1 \mathrm{~mm}$ region (Fig. 6.a and b), as they are relatively large and nearly morphologically aligned with WD in this region. As previously reported, chemical characterizations within the joint nugget did not 
(a)

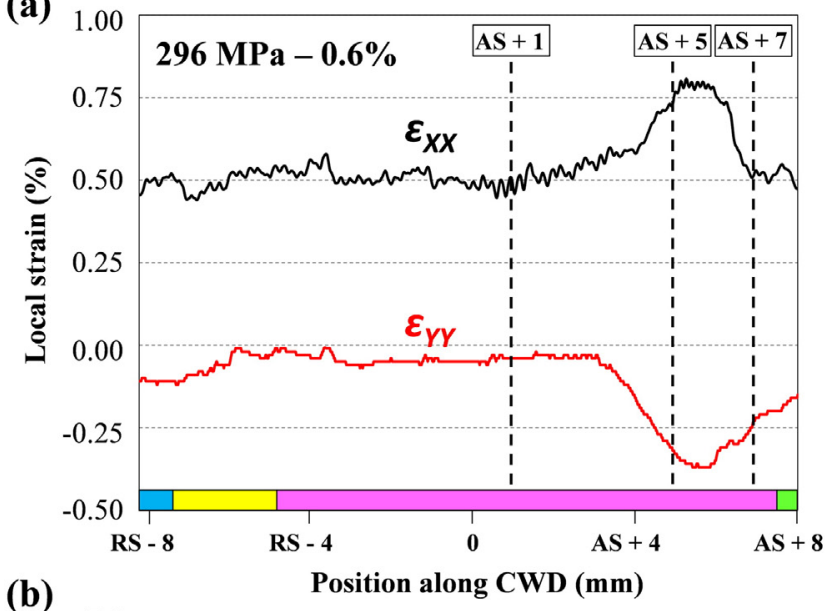

(b)

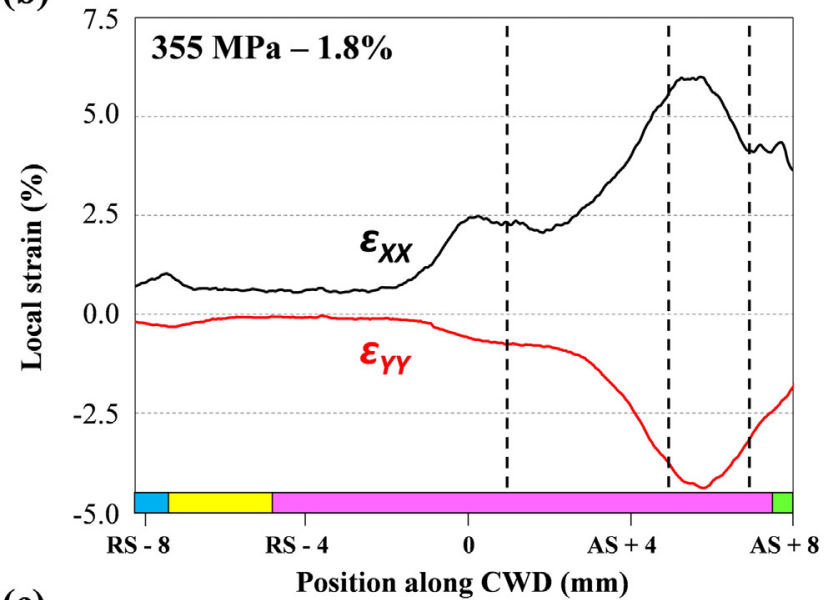

(c)

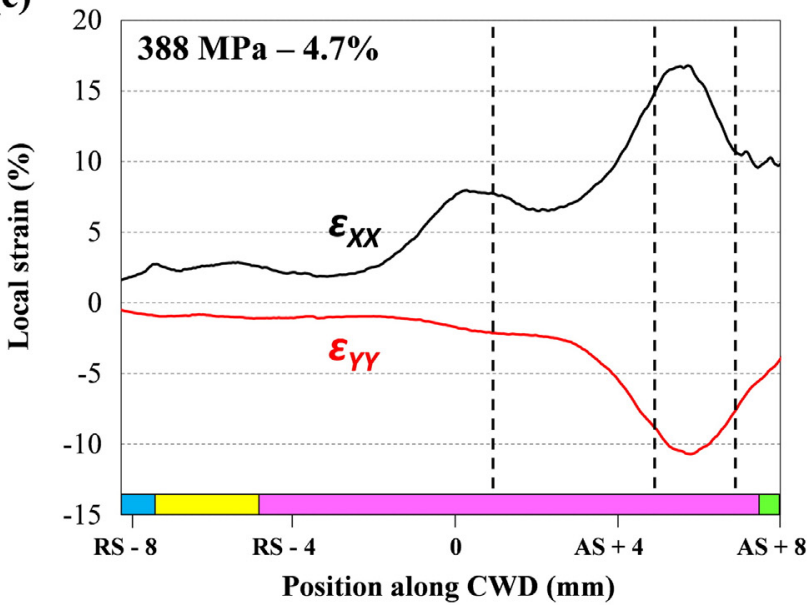

Fig. 10. Mean $\varepsilon_{X X}$ and $\varepsilon_{Y Y}$ values along CWD for various stress/strain conditions. a) $296 \mathrm{MPa}-0.6 \%$, b) $355 \mathrm{MPa}-1.8 \%$ and c) $388 \mathrm{MPa}-4.7 \%$ showing local strain concentration areas.

evidence strong material mixing between AA-2198 and AA-2024 in the nugget region [27]. The texture found in the banded AA-2198 side shoulder-affected region is different from the one observed in the AA-

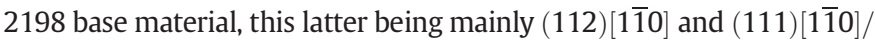
(111)[011] in relation with the normal direction [27].

The texture components of these bands can be related to the material flow generated by the FSW process. In Al alloys, crystallographic textures are generated according to the ease of $\{111\}$ crystallographic plane to align with the local maximal shear plane. As a result, Fonda et al. [18] have observed in a AA-2195 FSW joint the occurrence of the $\mathrm{B} / \overline{\mathrm{B}}((111)$ $[1 \overline{1} 0] /(111)[0 \overline{1} 1])$ and $C((110)[1 \overline{1} 0])$ components typical of simple shear textures if the texture is observed in the reference frame related to the rotation axis of the tool (as the bands are elongated in this direction). The main difference between the two strong texture fibers was the presence of the $\mathrm{C}$ texture component, revealing a difference in deformation mode between bands that can be associated with the various intensities of extrusion experienced in the mid-plane section of joints by each band during the revolution of the tool. Dhondt et al. [13] have also observed similar results on a AA-2050-T3 joint. In this case, the major texture components of the $\alpha$ fiber were the $A / C((112)[1 \overline{1} 0] /(110)[1 \overline{1} 0])$ texture component most likely due to the lower stalking force energy of this alloy.

In the present work, similar fibers and texture components were found, but in the reference frame constituted by the direction orthogonal to the revolution axis of the tool, which corresponds to the morphological elongation of the band. This difference outcomes from the fact that the bands documented in the present work were not the ones generated in the mid-plane section of joint but the ones below the shoulder. In the shoulder-affected region, the friction plane is orthogonal to the friction surface inferred by the tool pin, resulting in a 90 degrees rotation of the texture components. In addition, other differences such as texture components and intensity between the present work and other studies $[13,18]$ may depend on the process parameters and the alloy stacking fault energy, which all can strongly influence the deformation and the dynamic restauration process during FSW process.

The disappearance of the banded macroscructures towards the root side of the joint is also related to the variations in thermomechanical strain path experienced by the material from the shoulder and the root regions (Fig. 5). As previously mentioned, the material in contact with the tool (shoulder and pin) will undergo various plastic deformation history during one tool revolution depending of its relative position to the joint center and along the weld line [16-18,20,23,24]. Dissimilar joints clearly illustrate such behavior thanks to the well distinguishable bi-metals interface. The geometry of this interface inform on the strain evolution during this complex material process. It is believed that the saw-teeth shape of the bi-metal interface where banded macrostructures were found, witnesses the strain rate gradient existing during one rotation of the tool. This result is in good agreement with the fact that smooth/linear interface lead to homogeneous macrostructure, lacking bands. Therefore the pronounced texture fibers are believed to be less and less present in the underlying material, tending to an homogeneous AA-2198.

\subsection{Comparison between microhardness and OHR-DIC measurements}

The correlation between hardness measurements and the tensile deformation capability of the joint is not straightforward. In the region where necking and fractured will take place, low and high hardness bands (LHB/HHBs) correspond to high and low deformation bands (HDB/LDB), respectively (compare Fig. 12). Other paradoxes were found when comparing both techniques used to assess the local mechanical properties of the joint (Figs. 8 to 10): (a) On the retreating side, LHB/HHB periodic bands were identified by microhardness (Fig. 8.a) while homogeneous $\varepsilon_{X X}, \varepsilon_{Y Y}$ and $\varepsilon_{X Y}$ strain fields were homogeneous and uniform on the retreating side (Fig. 9); (b) The low hardness region located at RS- $4.5 \mathrm{~mm}$ does not present strain localization under uniaxial tensile loading and more generally low hardness regions (in Fig. 8.b) do not necessarily display high strain localization under tensile loading (compare with Fig. 9); (c) Reversely, the relatively high hardness region at RS-8 mm led to significant strain localization (Fig. 8 versus Fig. 9); (d) The abrupt transition in hardness at the AA2024/AA-2198 interface does not displays significant strain discontinuity nor high strain localization under tensile loading (Figs. 8 and 9). 

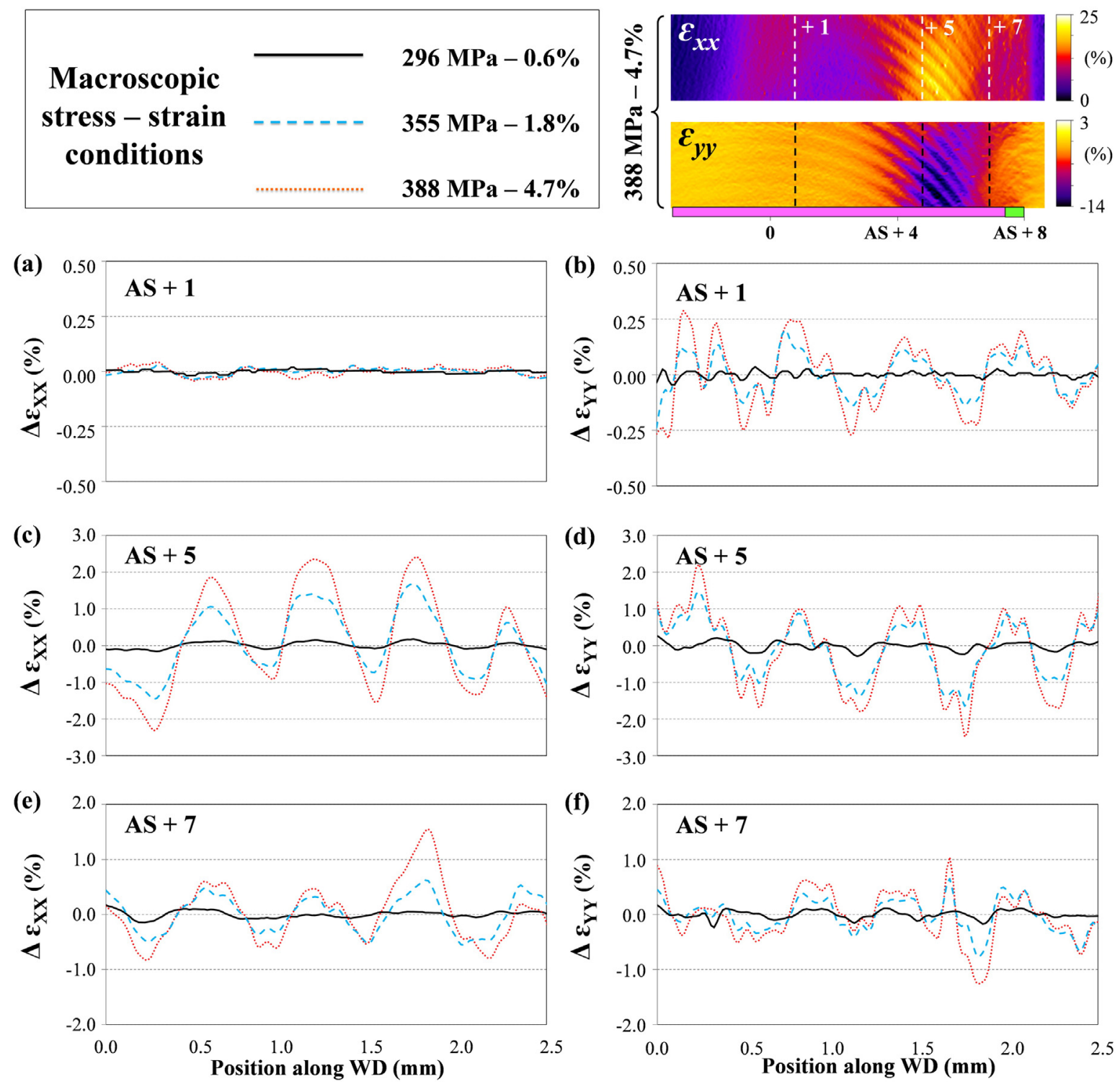

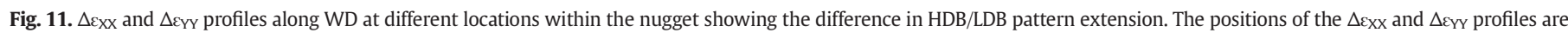
depicted as dashed lines in the top right insert. a) and b) AS $+1 \mathrm{~mm}, \mathrm{c}$ ) and d) AS $+5 \mathrm{~mm}$ and e) and f) AS $+7 \mathrm{~mm}$.

(a) $\prod_{W D} \mathrm{CWD}$

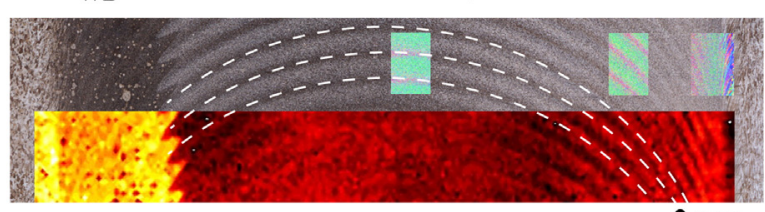

(b)

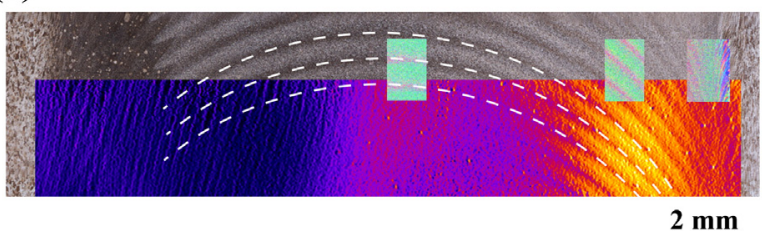

Fig. 12. Correlation between banded macrostructure, local mechanical properties and crystallographic texture. The $\langle 110\rangle$ fiber aligned with the metal flow direction (green area on the EBSD scan) correspond to HDB and LHB. (a) Emphasis on HHB/LHB pattern. (b) Emphasis on HDB/LDB pattern.
The discrepancies between the two measurements methods can be explained by the fact that the macroscopic loading stress applied under monotonic tensile testing is rather uniaxial while the stress state during indentation is complex and triaxial. Hardness is a quantitative property of materials that illustrates the capability of a material to resist permanent deformation. However, this capability of material to resist deformation is not necessary capable of predicting the uniaxial loading response of a material whose heterogeneities are mostly based on grain orientations and strong local crystalline textures. As OHR-DIC measurements reveal the strain heterogeneities in the elastic and plastic regime, the local information are specific to the observed grains orientation in reference to the imposed stress-state (Figs. 9 to 11). On the other hand, none-instrumented microhardness measurements unable the deconvolution of the elastic/plastic responses of the material; however, the elastic anisotropy of aluminum being low (the elastic moduli in pure aluminum range from 62.7 to $74.8 \mathrm{GPa}$ for the $\langle 001\rangle$ and $\langle 111\rangle$ orientations, respectively), a quasi-isotropic elastic behavior of aluminum in expected in the elastic regime [34], and the variability in hardness from band to band can be attributed to the anisotropic response of the material in the plastic regime [32,33]. Moreover, the deformation gradient generated below the indentation mark is 


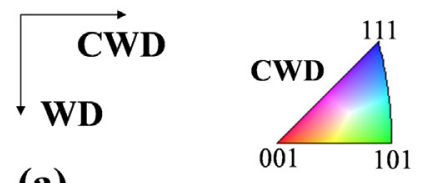

(a)

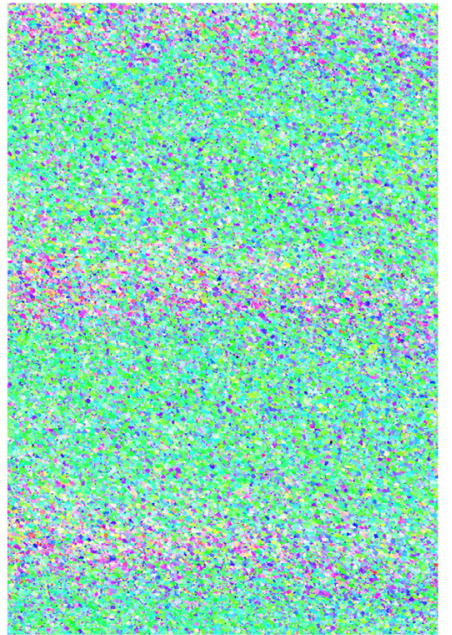

(d)

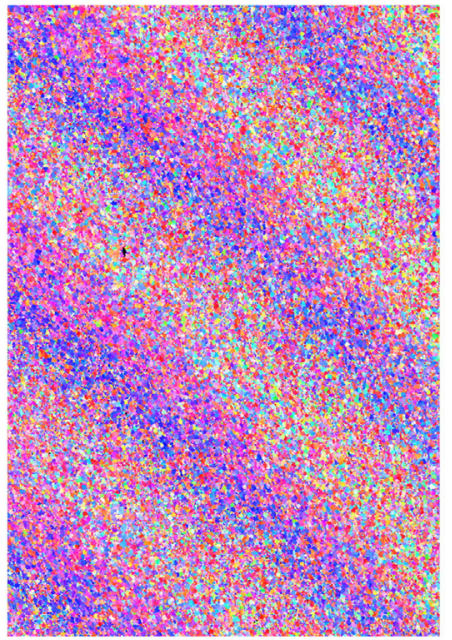

(g)

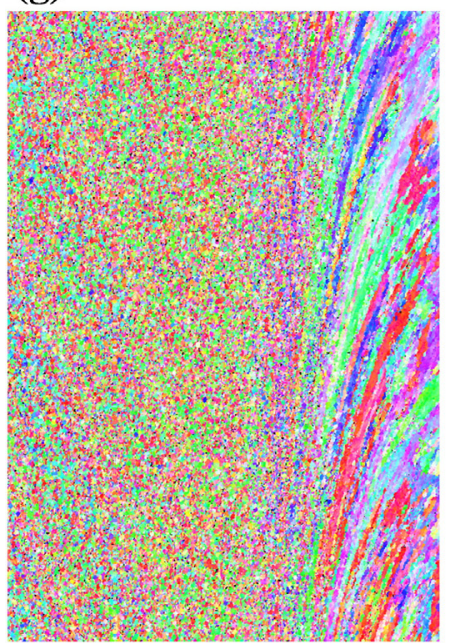

Elastic Moduli

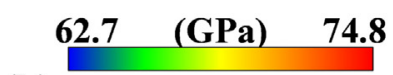

(b)

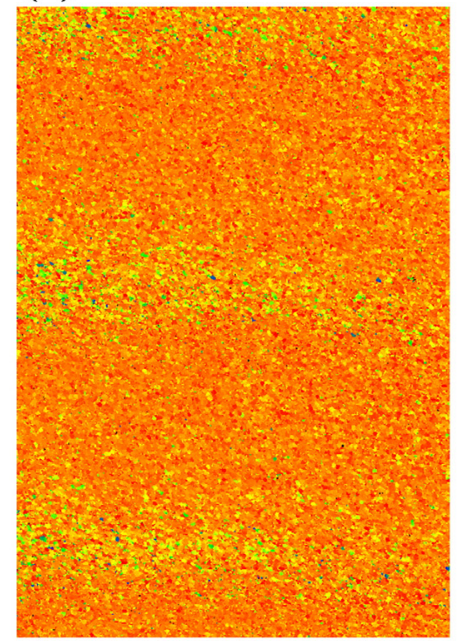

(e)

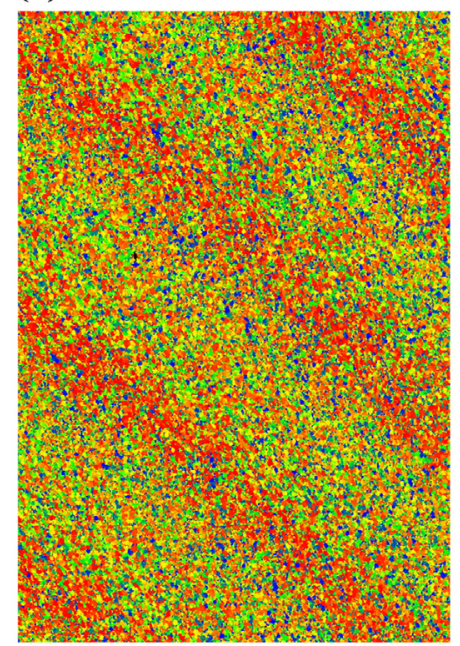

(h)

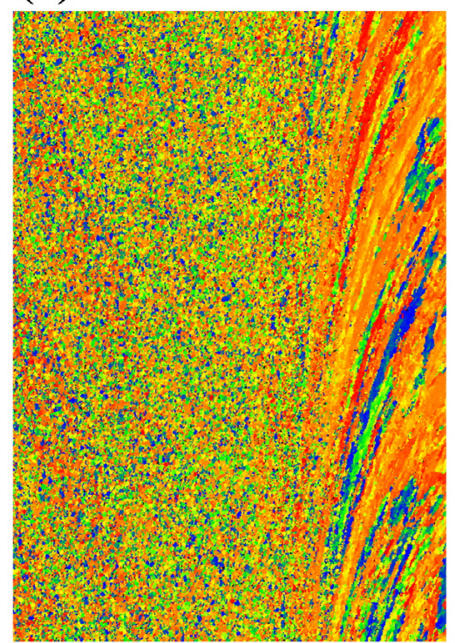

\section{Schmid factor}

(c)

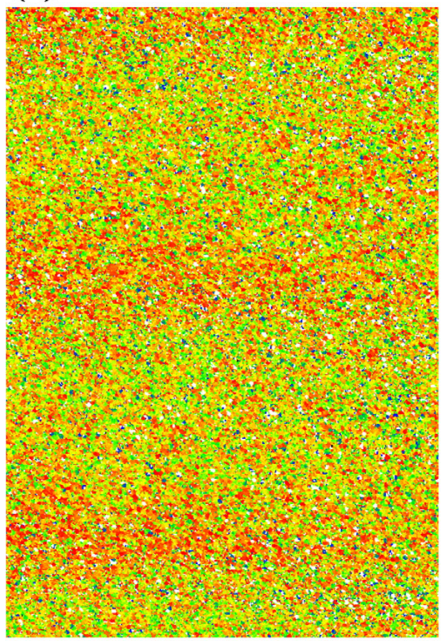

(f)

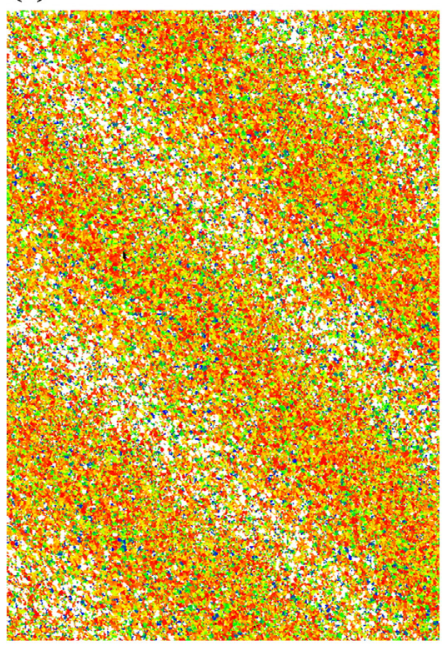

(i)

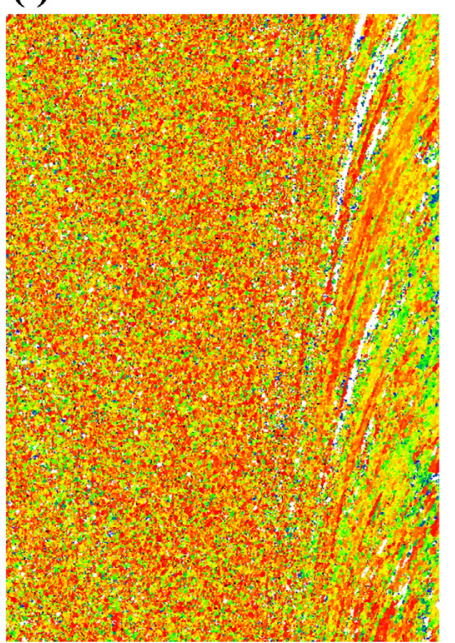

\section{$250 \mu \mathrm{m}$}

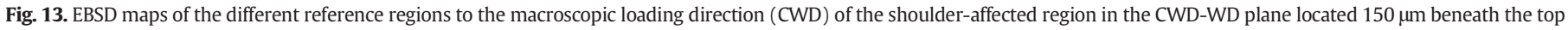

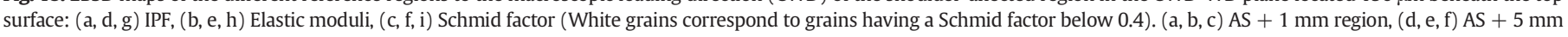
region, (g, h, i) AS + $7 \mathrm{~mm}$ region. 
much more complex than the deformation path imposed to the crystal during a simple tensile test. As a result, grain orientations that are seen as "soft" grains by the hardness measurement technique could actually end up being "hard" when observed during a uniaxial tension tests, explaining de facto some of the above paradoxes. Even if both techniques are relevant to reveal differences in local mechanical properties, the location of extreme values has no fundamental reason to coincide.

Banded macrostructures were found on both sides of the weld line (Fig. 5) and revealed by microhardness characterizations (HHBs/LHBs Fig. 8.a). However, HDBs/LDBs were revealed only on the advancing side (Figs. 9 and 12) by OHR-DIC. This statement can find explanation in the fact that both techniques, the macrostructure observation and the microhardness, characterize the "surface" region while the OHRDIC measurements average the volume behavior of the material in the thickness. For microhardness measurements, the plastic zone size ranges between 2.5 and 3.5 times the diagonal of the indent and 10 times the indent penetration, depending on the elastic/plastic properties [35]. With a 25 gf, Vickers indentation lead to a typical $20 \mu \mathrm{m}$ diagonal imprint, characterizing only the properties of the few first $50 \mu \mathrm{m}$ below the surface. On the other hand, due to stress/strain continuity in the material, the OHR-DIC "in-plane" deformations are the result of the underlying microstructure. On this aspect, the complex material flow during FSW generates a 3D structure and the behavior of a given region can be strongly influenced by the property of the adjacent region. The non-symmetrical "in-plane" response of the joint in OHR-DIC can illustrate such a volume effect. In fact, the 3D structure of the joint is not symmetrical as released by the serial sectioning technique and cross-section observations in Figs. 1 and 4. The AA-2024/AA-2198 boundary is highly inclined in the shoulder-affected region on the retreating side, starting at $\mathrm{RS}-5 \mathrm{~mm}$ on the Top surface and finishing close to the joint center on the bottom face of the specimen (Fig. 5.a and c). As the nugget AA-2024 material underlying the AA-2198 material in the retreating side presents a high resistance to deformation (Fig. 9), it will prevent the AA-2198 material to plastically deform as on the advancing side and no plastic localization will be monitored by the OHR-DIC technique. The underlying extension of AA-2024 is believed not to let the surface banded macrostructure to behave freely as on the advancing side, leading to the none-symmetric response of the weld. These observations suggest that if the banded regions are confined in a small enough volume, no sever plastic localization will take place due to deformation compatibility issues. On the other hand, if the banded structures are free to deform, significant plastic localization will take place, early necking will happen resulting in a ductile fracture of the joint.

\subsection{Effect of texture variation on the mechanical response under uniaxial loading}

As discussed above, in some favorable conditions, the differences in crystallographic orientations from band to band in the Top surface section of the joint will lead to a heterogeneous mechanical response of the joint and necking in the joint. To better understand the effect of such heterogeneities on the plastic response of the material, the crystallographic orientations of the three selected regions in Fig. 6 were processed to calculate the local elastic modulus and Schmid factor maps in reference of the loading direction. The results are displayed in Fig. 13.

The elastic moduli were calculated using the stiffness matrix of pure aluminum from Ref. [34]. Despite significant differences in crystallographic orientations from band to band, a low variation in elastic moduli is observed. It is therefore not surprising to observe a homogenous strain field across the FSW joint in the regions being still in the elastic regime (Fig. 9).

On the other hand, the maximal Schmid factors for all the 12 octahedral face-centered cubic (fcc) slip systems were calculated for all grains
(Fig. 13.c, f, and i), quantifying the ease for each grain to undergo early plastic deformation (the higher the Schmid factors the more prone is the orientation to activate dislocation gliding). The maps predict that these regions are expected to plastically deform in a heterogeneous manner when loaded close to the macroscopic plastic level, some regions having significantly lower Schmid factors than others. Interestingly, the periodicity of the Schmid factor depends on both, the crystallographic and morphologically orientation of the fibers according to the loading direction. While the "green" bands depicts relatively high Schmid factors in the three regions, the Schmid factors highly vary for the EBSD "pink" bands from relatively high values at AS $+1 \mathrm{~mm}$ and AS $+7 \mathrm{~mm}$ (Fig. 13.c or i) to low values at AS $+5 \mathrm{~mm}$ (white domains in Fig. 13.f). This banded macrostructure could be considered to act as a composite material with alternation of "hard" and "soft" regions in correlation with their level of local Schmid factor. The high magnitude of deformation variation from band to band could be responsible of the fracture of this heterogeneous material.

\section{Conclusions}

Microstructure evaluation, microhardness, EBSD measurements, and optical high resolution-digital image correlation (OHR-DIC) during tensile loading were used to document the heterogeneous nature and mechanical properties of the shoulder-affected region in a dissimilar aluminum joint obtained by FSW process. The following conclusions can be drawn:

1/ The shoulder-affected regions exhibit heterogeneous banded macrostructures in the top region of the joint. These bands tend to vanish few hundreds of micrometers beneath the surface.

2/ The local macroscopic strain localization leading to necking and failure was closely related to local crystallographic orientation heterogeneities. These banded macrostructures were found to be composed of two textured fibers, which present different plastic properties from band to band. In this regard, the shoulder-affected region of the joint can be considered as a composite material composed of "soft" and "hard" fibers. As these plastic properties are related to the morphology of the band, the local mechanical respond of this composite material vary according to the band orientation versus the loading direction. The mechanical response of this heterogeneous joint leads to the development of highly localized deformed regions, detrimental to the joint mechanical performance.

3/ The nonsymmetrical mechanical response of the Top surface nugget region of the joint leading to the systematic necking and failure on the advancing side was associated to the effect of the complex 3D macrostructure of the weld. While the microhardness technique was able to reveal the banded structure on both sides of the joint, this technique found limitations for predicting the complex behavior of the joint under tensile loading. Therefore, only the OHR-DIC technique under loading has demonstrated robust capabilities for proper evaluations of inhomogeneous joints, and more generally for heterogeneous materials.

\section{Acknowledgments}

The authors gratefully acknowledge Hossein Monajati and Nicolas Vanderesse for their technical support. The authors are particularly grateful to the Ministère de l'Économie, de la Science et de l'Innovation du Québec for the grant attributed via the Research Support Program (PSR), Component 4: Support for International Research and Innovation Initiatives (SIIRI) on the "Optimization of functional graded properties for aeronautic applications". This work was part of a research program supported by the Aluminum Research Centre - REGAL, a strategic cluster creating synergies between Québec's aluminum researchers. 


\section{References}

[1] N.D. Alexopoulos, E. Migklis, A. Stylianos, D.P. Myriounis, Fatigue behavior of the aeronautical Al-Li (2198) aluminum alloy under constant amplitude loading, Int. J. Fatigue 56 (2013) 95-105.

[2] W.M. Thomas, E.D. Nicholas, J.C. Needham, M.G. Murch, P. Templesmith, C.J. Dawes, Friction Stir Butt Welding, 9125978.8, n.d.

[3] R.S. Mishra, Z.Y. Ma, Friction stir welding and processing, Mater. Sci. Eng. R. Rep. 50 (2005) 1-78.

[4] C.J. Dawes, W.M. Thomas, Friction stir joining of aluminum alloys, TWI Bull. 6. (n.d.) 124-127.

[5] A.S. Hamada, A. Järvenpää, M.M.Z. Ahmed, M. Jaskari, B.P. Wynne, D.A. Porter, et al., The microstructural evolution of friction stir welded AA6082-T6 aluminum alloy during cyclic deformation, Mater. Sci. Eng. A 642 (2015) 366-376.

[6] M. Cabibbo, H.J. McQueen, E. Evangelista, S. Spigarelli, M. Di Paola, A. Falchero, Microstructure and mechanical property studies of AA6056 friction stir welded plate, Mater. Sci. Eng. A 460-461 (2007) 86-94.

[7] P.B. Srinivasan, K.S. Arora, W. Dietzel, S. Pandey, M.K. Schaper, Characterisation of microstructure, mechanical properties and corrosion behaviour of an AA2219 friction stir weldment, J. Alloys Compd. 492 (2010) 631-637.

[8] H. Aydın, A. Bayram, A. Uğuz, K.S. Akay, Tensile properties of friction stir welded joints of 2024 aluminum alloys in different heat-treated-state, Mater. Des. 30 (2009) 2211-2221.

[9] M.P. Miles, B.J. Decker, T.W. Nelson, Formability and strength of friction-stir-welded aluminum sheets, Metall. Mater. Trans. A 35 (2004) 3461-3468.

[10] Y. Uematsu, K. Tokaji, H. Shibata, Y. Tozaki, T. Ohmune, Fatigue behaviour of friction stir welds without neither welding flash nor flaw in several aluminium alloys, Int. J. Fatigue 31 (2009) 1443-1453.

[11] M.A. Sutton, B. Yang, A.P. Reynolds, J. Yan, Banded microstructure in 2024-T351 and 2524-T351 aluminum friction stir welds. Part II. Mechanical characterization, Mater. Sci. Eng. A 364 (2004) 66-74.

[12] B. Yang, J. Yan, M.A. Sutton, A.P. Reynolds, Banded microstructure in AA2024-T351 and AA2524-T351 aluminum friction stir welds, Mater. Sci. Eng. A 364 (2004) 55-65.

[13] M. Dhondt, I. Aubert, N. Saintier, J.-M. Olive, Mechanical behavior of periodical microstructure induced by friction stir welding on Al-Cu-Li 2050 alloy, Mater. Sci. Eng. A 644 (2015) 69-75.

[14] P.L. Threadgill, Friction stir welding - the state of the art, TWI Ind. Mem. Rep. 678 (1999) 678.

[15] K.N. Krishnan, On the formation of onion rings in friction stir welds, Mater. Sci. Eng A 327 (2002) 246-251.

[16] J.A. Schneider, J. Nunes, A. C., Characterization of plastic flow and resulting microtextures in a friction stir weld, Metall. Mater. Trans. B Process Metall. Mater. Process. Sci. 35 (2004) 777-783.

17] P. Heurtier, M.J. Jones, C. Desrayaud, J.H. Driver, F. Montheillet, D. Allehaux Mechanical and thermal modelling of friction stir welding, J. Mater. Process. Technol. 171 (2006) 348-357.
[18] R.W. Fonda, J.F. Bingert, Texture variations in an aluminum friction stir weld, Scr. Mater. 57 (2007) 1052-1055.

[19] Z.W. Chen, S. Cui, On the forming mechanism of banded structures in aluminium alloy friction stir welds, Scr. Mater. 58 (2008) 417-420.

[20] S. Xu, X. Deng, A study of texture patterns in friction stir welds, Acta Mater. 56 (2008) 1326-1341.

[21] S. Muthukumaran, S.K. Mukherjee, Multi-layered metal flow and formation of onion rings in friction stir welds, Int. J. Adv. Manuf. Technol. 38 (2008) 68-73.

[22] A.A.M. da Silva, E. Arruti, G. Janeiro, E. Aldanondo, P. Alvarez, A. Echeverria, Material flow and mechanical behaviour of dissimilar AA2024-T3 and AA7075-T6 aluminium alloys friction stir welds, Mater. Des. 32 (2011) 2021-2027.

[23] F. Gratecap, M. Girard, S. Marya, G. Racineux, Exploring material flow in friction stir welding: tool eccentricity and formation of banded structures, Int. J. Mater. Form. 5 (2012) 99-107.

[24] A. Tongne, M. Jahazi, E. Feulvarch, C. Desrayaud, Banded structures in friction stir welded Al alloys, J. Mater. Process. Technol. 221 (2015) 269-278.

[25] M.A. Sutton, B. Yang, A.P. Reynolds, R. Taylor, Microstructural studies of friction stir welds in 2024-T3 aluminum, Mater. Sci. Eng. A 323 (2002) 160-166.

[26] M.W. Mahoney, C.G. Rhodes, J.G. Flintoff, R.A. Spurling, W.H. Bingel, Properties of friction-stir-welded 7075 T651 aluminum, Metall. Mater. Trans. A 29 (1998) 1955-1964.

[27] H. Robe, Y. Zedan, J. Chen, H. Monajati, E. Feulvarch, P. Bocher, Microstructural and mechanical characterization of a dissimilar friction stir welded butt joint between AA2024-T3 and AA2198-T3, Mater. Charact. 110 (2015) 242-251.

[28] F. Bridier, J.-C. Stinville, N. Vanderesse, P. Villechaise, P. Bocher, Microscopic strain and crystal rotation measurement within metallurgical grains, Key Eng. Mater. 592-593 (2013) 493-496.

[29] J.C. Stinville, M.P. Echlin, D. Texier, F. Bridier, P. Bocher, T.M. Pollock, Sub-grain scale digital image correlation by electron microscopy for polycrystalline materials during elastic and plastic deformation, Exp. Mech. 56 (2016) 197-216.

[30] B. Pan, K. Qian, H. Xie, A. Asundi, Two-dimensional digital image correlation for inplane displacement and strain measurement: a review, Meas. Sci. Technol. 20 (2009) 062001

[31] S. Preibisch, S. Saalfeld, P. Tomancak, Globally optimal stitching of tiled 3D microscopic image acquisitions, Bioinformatics 25 (2009) 1463-1465.

[32] S.-H. Choi, F. Barlat, Prediction of macroscopic anisotropy in rolled aluminumlithium sheet, Scr. Mater. 41 (1999) 981-987.

[33] J. Chen, Y. Madi, T.F. Morgeneyer, J. Besson, Plastic flow and ductile rupture of a 2198 Al-Cu-Li aluminum alloy, Comput. Mater. Sci. 50 (2011) 1365-1371.

[34] G. Simmons, H.F. Wang, Single Crystal Elastic Constants and Calculated Aggregate Properties: A Hand Book, second ed., 1971 (Cambridge).

[35] M. Mata, O. Casals, J. Alcalá, The plastic zone size in indentation experiments: the analogy with the expansion of a spherical cavity, Int. J. Solids Struct. 43 (2006) 5994-6013. 